\title{
THE PREDICTIVE VALUE OF PERI-INFARCT FLOW TRANSIENTS IN FOCAL BRAIN ISCHEMIA
}

\author{
Ph.D. Thesis
}

János Lückl, MD

Szeged

2013 


\title{
THE PREDICTIVE VALUE OF PERI-INFARCT FLOW TRANSIENTS IN FOCAL BRAIN ISCHEMIA
}

\author{
By \\ János Lückl, MD \\ A Thesis for the Degree of \\ DOCTOR OF PHILOSOPHY \\ (Ph.D.)
}

In the Department of Medical Physics and Informatics,

Faculty of Medicine, University of Szeged

Consultant: Prof. Ferenc Bari, Ph.D., D.Sc.

2013

Szeged 


\section{TABLE OF CONTENTS}

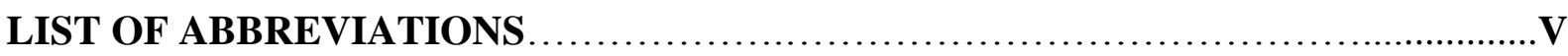

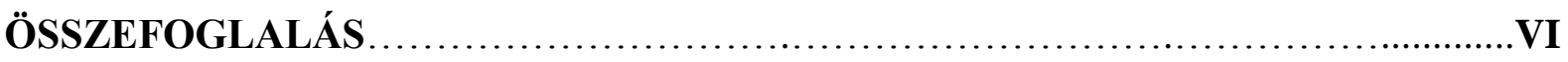

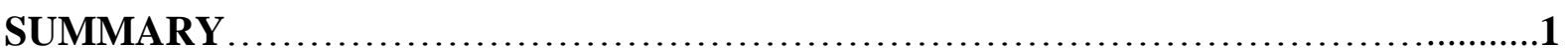

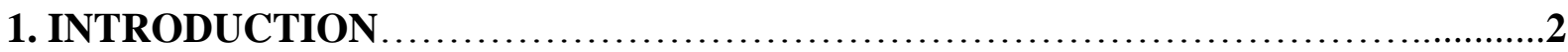

1.1 Mechanisms of spreading depolarization............................................

1.2 The role of spreading depolarizations in brain pathology.........................

1.3 The hemodynamic response to spreading depolarizations...........................5

1.4 Spreading depolarization as possible biomarker in experimental ischemia and clinical

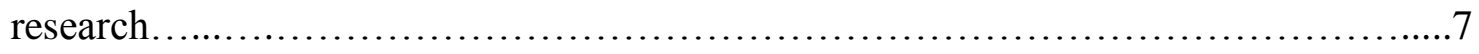

1.5 Hypotheses.....................................................................

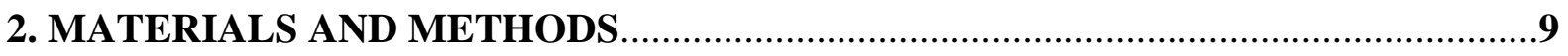

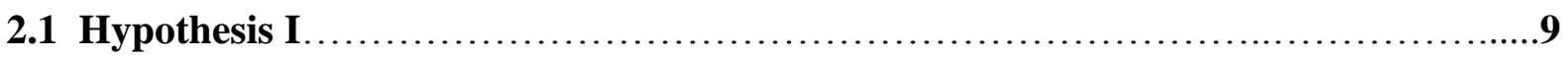

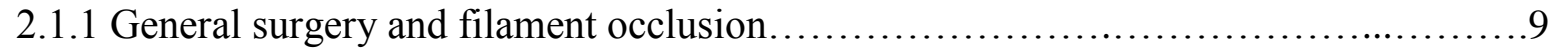

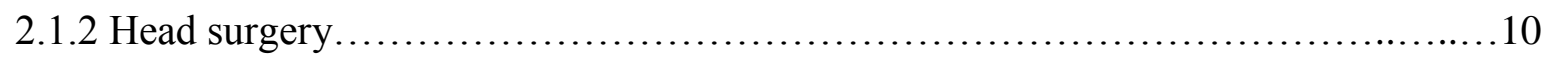

2.1.3 Electrophysiological recordings........................................ 10

2.1.4. Coupling of spreading depolarization with PIFTs............................11

2.2 Hypothesis II. ........................................................11

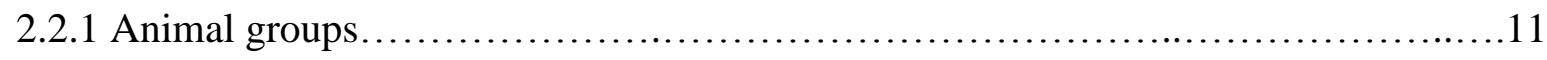


2.2.2 General surgery and filament occlusion.

2.2.3. Laser Doppler Flowmetry.

2.2.4 Infarct volume measurement.

2.3. Hypothesis III/a.

2.3.1 General surgery and filament occlusion.

2.3.2 Laser-speckle flowmetry: image acquisition and post-processing. ...

2.3.3 The identification of PIFTs....

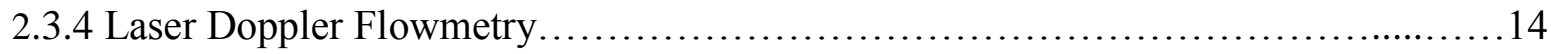

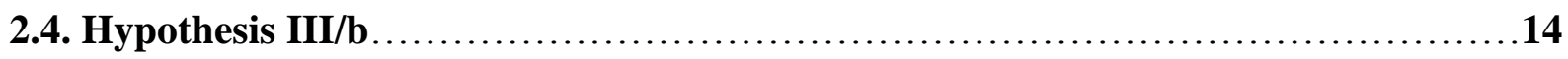

2.4.1 Photochemically induced distal middle cerebral artery occlusion..................14

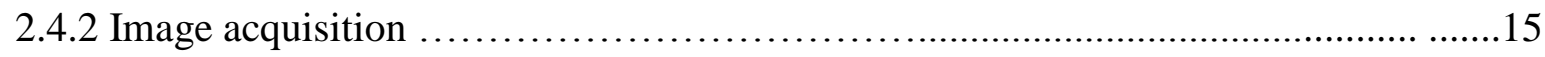

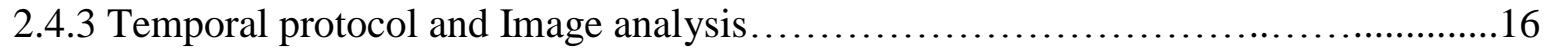

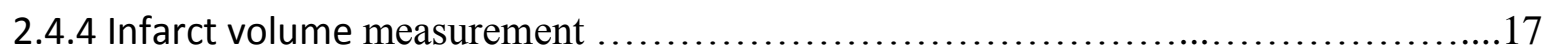

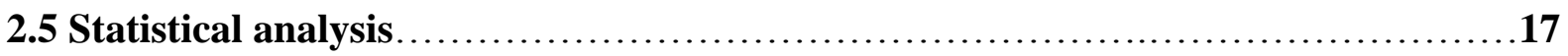

3. RESULTS

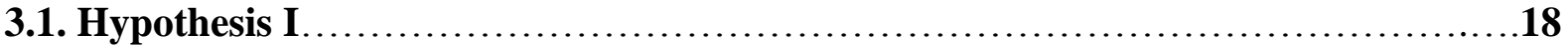

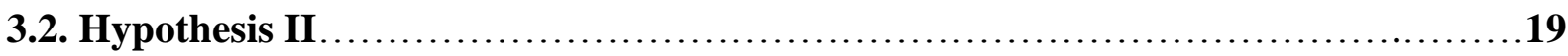

3.2.1 PIFT parameters and outcome .............................................. 19

3.2.2 Logistic regression analyses of single parameters............................... 21

3.2.3 Logistic regression analyses of combinations of parameters......................22 


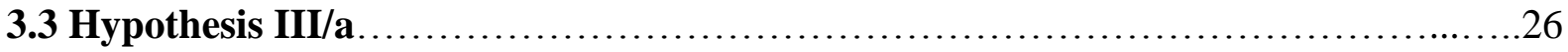

3.3.1 Morphology of PIFTs................................................... 26

3.3.2 Amplitudes of PIFTs.................................................... 30

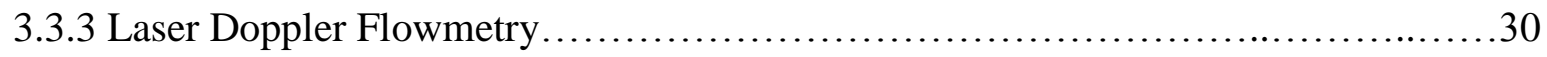

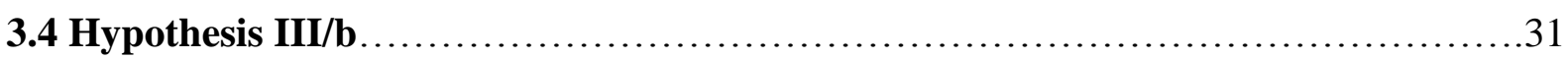

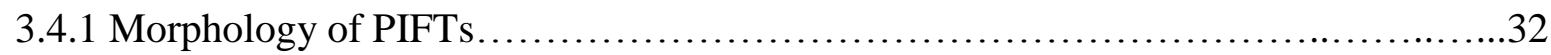

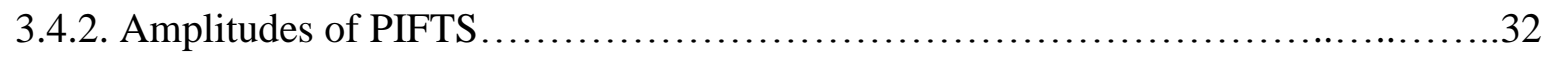

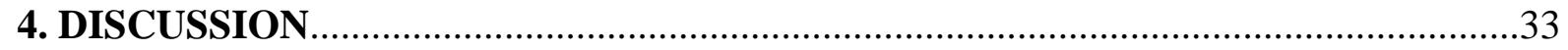

4.1 The coupling rate between DC changes and PIFTs............................ 33

4.2 The predictive value of PIFTs with regards to the histological outcome................33

4.3 The predictive value of the morphological heterogeneity of the PIFTs.................35

4.4 Laser speckle versus laser Doppler measurements............................36

4.5 The possible role of PIFT as biomarker in animal research........................38

4.6 The possible role of PIFT as biomarker in clinical studies..........................38

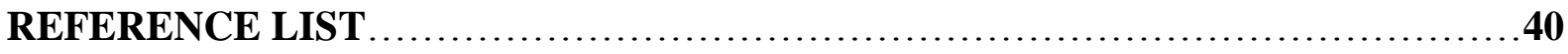

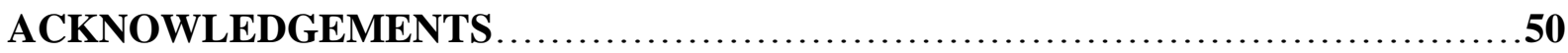

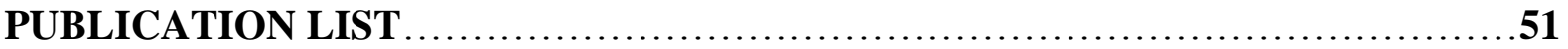




\section{LIST OF ABBREVIATIONS}

ACA - anterior cerebral artery (ACA)

CBF - cerebral blood flow

CCA - common carotid artery

CPA - correctly predicted animals

DC - direct current

ECoG - Electrocorticography

EEG - Electroencephalography

HALO - halothane anesthetized animals

ISO - isoflurane anesthetized animals

LD - laser Doppler

LS - laser Speckle

MCA - middle cerebral artery

MCAO - occlusion of the middle cerebral artery

NMDA - N-methyl-D-aspartate

NO - nitric oxide

PID - peri-infarct depolarization

PIFT - peri-infarct flow transients

ROI - region of interest

SD - spreading depolarization

TTC - 2,3,5-triphenyltetrazolium chloride 


\section{ÖSSZEFOGLALÁS}

Állatkísérletes adatok alapján a kúszó depolarizációk (KD) fontos szerepet játszanak az agyi károsodás progressziójában, és így biomarkerként szolgálhatnak minden KD-hez kapcsolható kórképben. Biomarkerek alkalmazása segíthet az állatkísérletes és klinikai kutatás közötti transzlációs blokkok áthidalásában. A KD-k klinikai, elektrofiziológiai észlelése már most is zajlik invazív módon olyan betegekben, akiknek állapota megköveteli a koponya megnyitását (pl. subarachnoidális vérzés, malignus lefolyású arteria cerebri media infarktus, és súlyos fejsérülés). Ugyanakkor, a KD-k non-invazív, koponyán kívüli monitorizálása lehetővé tenné a klinikusok számára sokkal nagyobb betegpopuláció (pl. összes ischaemiás stroke vagy enyhe fejsérülés) korai vizsgálatát. Az KD-k extrakraniális detektálásának nehézségei miatt fordul a figyelem egyre inkább az alternatív biomarkerek, pl. az ún. peri-infarct áramlási tranziensek (PIT) irányába, amelyek a KD-k hemodinamikai kísérőjelenségei. Munkánk fő célja az volt, hogy megvizsgáljuk állatkísérletekben, vajon a PIT paraméterei (előfordulási gyakoriság, és az amplitúdó) önmagukban vagy kombinálva más áramlási paraméterekkel (pl. az ischémia soran mérhetö áramlás, ill. reperfúzió mértéke) a szövettani károsodásra vonatkozóan prediktívek-e. Megvizsgáltuk azt is, hogy az áramlási tranziensek amplitúdója, ill. morfológiája mutat-e regionális heterogenitást, és ez által alkalmas lehet-e az ischémiás mag, a penumbra és a peri-ischémiás területek elkülönítésében. Először, filament okklúziós modellben $(\mathrm{n}=32)$ meghatároztuk a kapcsoltság mértékét a KD-k valamint a PIT-ek között. Azt találtuk, hogy a lézer Doppler áramlásméréssel mért PIT-ek nagyfokban, mintegy 93\%ban mutatattak időbeli kapcsoltságot az epidurálisan, ezüstklorid elektródok segítségével regisztrált KD-kal. A filament okklúziós állatok $(\mathrm{n}=55)$ post hoc elemzése kimutatta, hogy az ischémia során mért véráramlás mértéke és a PIT-ek számának együttes kombinációja a legjobb, korai biomarker a szövettani kimenetel meghatározásában. Elemeztük az áramlási tranziensek amplitúdójának és morfológiájának térbeli eloszlását is mind filament okklúziós $(\mathrm{n}=10)$ mind fotókémiai úton indukált stroke $(\mathrm{n}=8)$ modellekben. A vizsgálatok azt mutatták, hogy az alacsonyabb áramlási értékek, a kisebb amplitúdó valamint a hipoperfúzív PIT-ek nagyobb előfordulási aránya jellemzi a penumbrát. Jobb perfúzió, nagyobb amplitúdók és a hiperémiás jellegü PIT-ek gyakoribb előfordulása jelzi a peri-ischémiás területeket. Az eredményeink arra utalnak, hogy a PIT-ek potenciális biomarkerek lehetnek humán vizsgálatokban. 


\section{SUMMARY}

Animal studies have been shown that spreading depolarizations (SD) play an important role in lesion progression during focal ischemia. Therefore SDs might serve as biomarkers of injury progress in ischemic stroke and in other SD related disorders in order to overcome translational roadblocks. Electrophysiological recordings of SDs have already been performed in human studies, where the patient's condition requires craniotomy (for example subarachnoid haemorrhage, malignant middle cerebral artery infarction and severe traumatic brain injury). However, a non-invasive, extracranial monitoring of SDs would allow investigators to enroll a larger patient population (all the patients with ischemic stroke and minor head trauma) immediately after the injury onset into the studies. The limitations of extracranial recording of SDs turn the interest into monitoring alternative biomarkers such as peri-infarct flow transients (PIFTs) which are the hemodynamical correlates of SDs in stroke. The aim of this thesis was to investigate if the parameters of the PIFTs (number and the amplitudes) alone or combined with other flow parameters (intra-ischemic flow, level of reperfusion) collected by laser Doppler can predict histological outcome in experimental ischemic stroke. We hypothesized also that the amplitude and the morphology of flow transients show regional heterogeneity and therefore it can be helpful in distinguishing the ischemic core, penumbra and peri-ischemic area. We first determined the coupling rate between the DC deflections and PIFTs in a model of filament occlusion $(n=32)$ and found that $93 \%$ of the PIFTs recorded by an LD probe are tightly coupled to DC deflections recorded by epidural silver chloride electrodes. The post hoc analysis of filament occluded animals $(n=55)$ revealed that the combination of intra-ischemic blood flow and the number of PIFTs together is a good, early predictor of histological outcome. The spatial distribution of the amplitudes and the morphology were analyzed both in the filament occlusion model $(n=10)$ and in the photo chemically induced distal occlusion of the middle cerebral artery $(n=8)$. We found that lower residual flow, smaller amplitudes and a higher percentage of hypoperfusive flow transients is characteristic for penumbral areas, especially closer to the core. A higher residual blood flow and amplitude of flow transients along with a larger percentage of hyperemic and hyperemia dominant biphasic flow transients indicates peri-ischemic area. We conclude that PIFTs are potential biomarkers in human studies. 


\section{THE PREDICTIVE VALUE OF PERI-INFARCT FLOW TRANSIENTS IN FOCAL BRAIN ISCHEMIA}

\section{INTRODUCTION}

\subsection{Mechanisms of spreading depolarizations}

The first paper on the phenomenon called spreading depression was published by Aristides Leao (Leao, 1944). His original aim was to investigate the propagation of experimentally induced seizures, but he detected the flattening of the electrocorticographic (EcoG) activity, which crept slowly over the cortex. Later, he recorded from the cortical surface a large, negative potential shift ( -5 to $-15 \mathrm{mV}$ ) called spreading depolarization (SD) associated with a spreading depression (Leao, 1947). Decades of research have shown that SD can be induced by many noxious conditions, including mechanical damage, electrical stimulation, hyperthermia, chemical stimuli such as potassium, the neurotransmitters glutamate and acetylcholine, hypoglycemia, hypoxia and ischemia (Leao, 1947, Hossmann, 1994, Somjen, 2004). SDs have been recorded in virtually all the gray matter regions, but are triggered more easily in the CA1 sector of the hippocampus, closely followed by the neocortex (Somjen, 2004). The induction of SDs in the cerebellar cortex and the spinal cord can be achieved only under special conditions (Nicholson, 1984, Czeh and Somjen, 1990) while in very young animals SD cannot be elicited at all (de Neverlee and Laget, 1965). The role of species differences has also been discussed in the literature with Strong and Dardis concluding that species differences may have to do with the susceptibility to spreading depolarization (Strong and Dardis, 2005). The neuron density decreases with increasing brain size in mammals (Tower and Young, 1973) with the dominance of glial elements being likely implicated in the relative protection against SDs in larger animals (Somjen, 2004). Selectively poisoning glial cells or interrupting gap junctions between them enhances SDs (Largo et al., 1996, Largo et al., 1997, Theis et al., 2003). It appears that glial cells play a passive role in SD (Walz, 1997). Glial depolarization is mainly passive with astrocytes taking up extracellular $\mathrm{K}^{+}$during $\mathrm{SD}$, while neurons release it. It is important to note, however, that neurons and their dendrites are the active players of SD. They store electrochemical energy by ion gradients and electrical 
charges across the membrane. Neurons act like a miniature biological battery which is a basic precondition for action potential and information processing. The high-energy consuming sodium pump maintains the homeostasis of ion gradients which can be upset by various noxious stimuli like ischemic stress. Actually, the term of spreading depolarization denotes the breakdown of this homeostasis (Dreier, 2011). First, Collewijn and Van Harreveld recorded the intracellular potential of neurons during SD and concluded that the membrane potential of neurons never reaches zero (Collewijn and Harreveld, 1966). This near-complete depolarization of the neurons (Somjen and Aitken, 1984, Czeh et al., 1993) is accompanied by the decrease of membrane resistance (Czeh et al., 1993), the loss of electrical activity (Leao, 1944), neuronal swelling and distortion of dendritic spines (Takano et al., 2007), and cytotoxic edema (Kraig and Nicholson 1978; Takano et al 2007). The depolarization is mediated by $\mathrm{Na}^{+}$influx (Martins-Ferreira et al., 1974, Muller and Somjen, 2000b) with the apical dendrites being the primary generators (Wadman et al., 1992). Whilst the influx of extracellular $\mathrm{Ca}^{2+}$ has major consequences in cell injury (Siesjo, 1993), it is not necessary for SD (Ramos, 1975, Basarsky et al., 1998). Similarly, neither synaptic transmission nor neuron firing is a basic prerequisite for SD generation (Kow and van Harreveld, 1972, Mori et al., 1976, Muller and Somjen, 2000a). Both extracellular $\mathrm{K}^{+}$and glutamate, however, are involved in the evolution and propagation of SD (Van Harreveld and Fifkova, 1970, Obrenovitch and Zilkha, 1995, Kager et al., 2000). Although the core process of spreading depolarization can be modeled in a single neuron (Kager et al., 2002), it usually spreads at a rate of 2-6 mm/min. (Lauritzen, 1994). Direct inter-neuronal gap junctions bring cells presumably into synchronous operation and provide a transcellular pathway for the propagation of SDs (Herreras et al., 1994, Somjen, 2004). The idea of gap junctions is currently under scientific critique (Somjen, 2004). For example, it has been recently reported, that the selective gap junction blocker carbenoxolone failed to block SDs (Vilagi et al., 2001). A few alternative, computational models describe SD propagation as a diffusionreaction process (Tuckwell, 1981, Davydov and Koroleva, 1993) where assumptions are made about the diffusion of $\mathrm{K}^{+}$(and other humoral agents) in the interstitium and the reactions governing the substrate release. 


\subsection{The role of spreading depolarizations in brain pathology}

A physiological role of SD is unlikely, as it does not evolve in healthy tissue. However, SD bears a Janus-faced character. On the one hand SDs have a neuroprotective feature by inducing precondition, facilitating plasticity and promoting regeneration (Matsushima et al., 1996, Yanamoto et al., 2005) while on the other hand there is a strong experimental and clinical experience that $\mathrm{SD}$ is associated with brain injury such as ischemic stroke, subarachnoid hemorrhage and traumatic brain injury (Lauritzen et al., 2011). Noxious stimuli induce SD when the net inward current outlasts the outward current (Somjen, 2004). SD triggers intracellular signals and protease leading to death if sustained depolarization exceed a certain time duration (“commitment point") (Dijkhuizen et al., 1999, Somjen, 2004). Potential mechanisms by which prolonged spreading depolarizations may cause tissue cell death include intracellular calcium overload, which reaches a maximum of about $25 \mu \mathrm{M}$ in living neurons, as measured during both short-lasting and terminal depolarization (Dietz et al 2008). Moreover, the breakdown of ion homeostasis is the principal cause of glutamate transporter reversal, which entails maximal release of glutamate (Rossi et al 2000). This indicates that excitotoxicity and SD are largely overlapping phenomena. Travelling from the tissue exposed to the noxious stimulus, spreading depolarization can invade naive tissue. Although subcellular processes change depending on the nature of the noxious stimulus (Dietz et al., 2008), SD spreads in the tissue along a gradient from a high to an increasingly lower concentration of the noxious stimulus (Aitken et al., 1998). Local recovery depends on sufficient energy-dependent recruitment of sodium pump activity (La Manna, 1975), which can be severely disturbed under noxious conditions. Low doses trigger single, short-lasting events (Nozari et al., 2010). Spreading depolarization is called terminal spreading depolarization in regions where the neurons do not repolarize (Farkas et al., 2010). Terminal depolarization is always associated with neuronal death (Saito et al., 1997), while neurons survive short-lasting spreading depolarization (Nedergaard and Hansen, 1988, Nozari et al., 2010). Naive brain tissue tolerates many repeated SD episodes (Nedergaard and Hansen, 1988) but the metabolic stress becomes apparently excessive when the blood supply declines (Hossmann, 1994). In experimental ischemia SD, apart from the first SD starting in the core propagates from the border zone between core and penumbral region. These SDs are often circling around the core (Nakamura et al., 2010), and are often referred to as peri-infarct 
depolarization (PID) (Hossmann, 1996). Both the frequency of the SD waves and the depolarization time correlate with the infarct growth (Mies et al., 1993, Dijkhuizen et al., 1999). SDs can be modulated pharmacologically both in animal and human brain. N-methylD-aspartate (NMDA) antagonists can inhibit both the SD waves and the growth of the injury (Iijima et al., 1992, Hossmann, 1994, Hertle et al., 2012). However, if the energy depletion is severe, NMDA antagonists lose both their efficacy against SDs and their protective effect. This pharmacoresistance of SDs to NMDA antagonists is presumably due to the gradual increase in the baseline extracellular potassium concentration preceding the first SD under energy depleted conditions (Muller and Somjen, 2000a). In fact, an artificial increase in baseline extracellular alone, without any energy depletion, is sufficient to render SDs resistant to NMDA antagonists (Petzold et al., 2005).

\subsection{The haemodynamic response to spreading depolarisations}

Neurovascular coupling is a well established concept (Roy and Sherrington, 1890) which describes the tight coupling between brain metabolism and regional cerebral blood flow (CBF). The coupling is coordinated by events involving neurons (Domoki et al., 1999, Busija et al., 2007), glia (Iadecola and Nedergaard, 2007), perivascular nerves (Goadsby and Hoskin, 1994, Busija, 1996) and vascular cells (Girouard and Iadecola, 2006). Vasoeffectors such as nitric oxide (NO), adenosine and prostanoids are also released (Busija et al., 2008). SD shares several features with physiological neuronal activation. The main dilator agents are calcitonin gene-related peptide release by trigeminal afferents (Colonna et al., 1994, Reuter et al., 1998, Bari and Paprika, 2000), the acetylcholine release from perivascular nerves (Reuter et al., 1998) and NO derived from neural sources (Colonna et al., 1997). Prostaglandins reduce constriction in parenchymal and pial resistance vessels (Shibata et al., 1992). In his original demonstration Leao showed that the depolarization event in the rabbit brain was associated with the transient dilation of the pial arteries (Leao et al., 1944). Pial arterioles show approximately a 30-50\% change in diameter depending upon to the species and the mode of initiation (Meng and Busija, 1996, Bari et al., 1998b, Ayata and Moskowitz, 2006, Brennan et al., 2007). Spreading depolarizations can evoke a CBF rise by more than $100 \%$ (Lauritzen, 1994). Hansen et al were able to demonstrate, using radioactively labeled iodoantipyrine in anesthetized rats, that SDs are indeed coupled with a large increase of CBF (Hansen et al., 1980). Despite this pronounced CBF increase, tissue hypoxia may develop in most distant 
supply territories of cortical capillaries (Takano et al., 2007) as the hyperemia is inadequate to cover the increased metabolic demand (Piilgaard and Lauritzen, 2009). Tissue adenosine-5 triphosphate decreases, glucose utilization triples, lactate is released and extracellular $\mathrm{pH}$ falls (Mutch and Hansen, 1984, Somjen, 2004, Windmuller et al., 2005).

Over the past few decades variability in CBF responses has been reported. Most studies report a biphasic CBF change with a large hyperperfusion shortly after the direct current potential shift followed by a long lasting hypoperfusion (Goadsby et al., 1992, Seitz et al., 2004). Some studies also observe that before the hyperemic phase, there is a transient hypoperfusion (Dreier et al., 2001, Ayata et al., 2004). The magnitude and the shape of the CBF changes can be homogeneous with repeated SDs (Bari et al., 2000) or vary with time (Fabricius et al., 1995). The reasons for these different vascular responses are unknown, but the mode of initiation of SDs, the physiological status of the animal, and the anesthesia might be relevant factors. In addition species difference has been reported. Vasoconstrictive coupling was observed during SD in mice but not in adult rats using laser Doppler (LD) flowmetry (Ayata et al., 2004).

Pathological conditions influence the CBF response (Bari et al., 1998a, Sukhotinsky et al., 2008, Sonn and Mayevsky, 2012). An inverse hemodynamic response (prolonged hypoperfusion) due to severe arteriolar constriction that is coupled to spreading depolarization has been observed under conditions likely to be present in patients following SAH (Dreier et al., 1998). Conversely, Iijima et al have reported that the blood flow responses to PIDs, the so called peri-infarct flow transients (PIFT), are hyperemic in focal cerebral ischemia when monitored with laser Doppler (LD) (Iijima et al., 1992). Similarly, the flow data collected in our early studies by one or two laser Doppler probes at different recording sites in the ischemic cortex of rats indicated that the flow transients are mostly hyperemic events (7090\%) and do not show regional heterogeneity. However, laser speckle studies show that the flow transients are polymorphic. For example, Shin and colleagues reported repetitive PIDs associated with hypoperfusion or biphasic transients in mice subjected to middle cerebral artery (MCA) occlusion (Shin et al., 2006). 


\subsection{Spreading depolarization as possible biomarker in experimental ischemia and clinical research}

The traditional classification of research distinguishes two main categories: basic research and applied research. Medical translational research focuses on the interface between experimental basic science and clinical medicine. It translates knowledge and techniques discovered by basic research quickly into new approaches for diagnosis and treatment of diseases. However, the road from bench to bedside appears more difficult than expected. For example, despite decades of rigorous scientific work in stroke research, the recanalization of the ischemic brain region via thrombolysis by recombinant tissue plasminogen activator is the only approved stroke treatment in the US and in Europe. Part of translational research involves the development of biomarkers which can help overcome this translational roadblock. Biomarkers can be used for many purposes including diagnosis, prognosis and the selection of appropriate patient therapy, and can provide information on disease mechanism and progression.

Since studies have shown that spreading depolarization play an important pathophysiological role in lesion progression during focal ischemia (Hossmann, 1996, Dijkhuizen et al., 1999, Shin et al., 2006, Nakamura et al., 2010), SDs could serve as biomarkers especially in quality control of experimental ischemia (for example in treatment stratification) or as an indicator of the injury progress. However, the direct current (DC) recording requires substantial equipment, and is invasive (intra-cortical) if microelectrodes are intended for use. Therefore the widespread application of DC detection in routine is not practical. On the other hand, the measurement of flow transients associated with SDs in animal research is feasible even with a single LD probe.

Electrophysiological biomarkers in clinical research of SD related disorders are also under investigation. Hartings et al reported that prolonged DC shifts with isoelectric depolarizations were more commonly associated with poor outcome in neurotrauma patients (Hartings et al., 2011). A simultaneous full-band direct and alternating current ECoG at the scalp and direct and alternating current ECoG recording at the cortical surface were made in patients with aneurismal subarachnoid haemorrhage and with malignant hemispheric stroke (Drenckhahn et al., 2012). That study revealed that the slow and the ultraslow potential 
changes, which contribute to the infarct evolution (Herreras and Somjen, 1993, OliveiraFerreira et al., 2010), were detectable both on the cortical surface and at the scalp with a coupling rate of $70.2 \%$. Despite some technically limiting factors such as inverse filtering (if a DC-coupled amplifier is not available) etc. (Hartings et al 2011), the combined bed-side recording of the scalp ultraslow potential, slow potential and depression of spontaneous activity looks very promising in on-line detection of injury onset and progression in patients with subarachnoid hemorrhage and traumatic brain injury. The electrophysiological recordings in these studies are performed invasively after craniotomy and 24-72 hours after the injury onset. However, non-invasive, extracranial monitoring of SDs would allow investigators to enroll a larger patient population (patients with non-malignant ACM thrombosis and mild traumatic brain injury etc.) into the studies and immediately after the acute event. Although the non-invasive recording of single slow potential with scalp electroencephalography (EEG) would also be possible in the acute phase of human ACM thrombosis unfortunately the coupling rate is relatively low (Drenckhahn et al 2012). The non-invasive detection of the surrogate events of SDs as PIFTs might be a good alternative for a single or combined (with electrophysiology) monitoring. A non-invasive, bed-side measurement of $\mathrm{CBF}$ with near infrared or diffuse correlation spectroscopy is already available (Obrig and Villringer, 2003, Durduran et al., 2010).

\subsection{Hypotheses}

In experimental ischemia models we tested if flow transients could be a potent biomarker in stroke research. We used LD and LS as closely related optical methods for monitoring flow changes. LD flowmetry uses the frequency shift produced by the Doppler-effect to measure velocity and can be used to measure blood flow at a single point. In LS flowmetry, scattered laser light produces a random interference pattern known as speckle, whose fluctuations delivers information about the motion of particles in the underlying medium. LS flowmetry provides real-time two-dimensional CBF imaging, a clear advantage over LD scanning techniques (Briers, 2001). The following parameters of flow transients can be measured easily and quickly in experimental ischemia: the number, the amplitude and the morphology. 
Our hypotheses are the followings:

I. We hypothesize, that flow transients are well coupled to the negative DC shift (the gold standard for the recording of spreading depolarization). Since the literature lacks relevant data on the coupling rate, a filament occlusion study was performed in rats to validate that the PIFTs were coupled to typical DC shifts.

II. We hypothesize, that the parameters of the PIFTs (number and the amplitudes) alone or combined with other flow parameters (intra-ischemic flow, level of reperfusion) collected by a single LD probe can predict histological outcome. We have performed a post-hoc analysis of our MCA occlusion (MCAO) studies. Based on findings in 55 filament occluded animals we tested if the flow parameters alone as single markers or in any combinations can predict the presence of cortical infarct.

III. We hypothesize that the amplitude and the morphology of flow transients show regional heterogeneity ad therefore it can be helpful in distinguishing the ischemic core, penumbra and peri-ischemic area. We analyzed the spatial distribution of the amplitudes and the morphology in two different models of focal ischemia: a, proximal MCAO (filament occlusion) and in $\mathbf{b}$, distal MCAO (photochemically induced) study.

\section{MATERIALS AND METHODS}

All procedures performed were approved by the Institutional Animal Care and Use Committee of the University of Pennsylvania.

\subsection{Hypothesis I}

\subsubsection{General surgery and filament occlusion}

Adult male Sprague-Dawley rats $(290-340 \mathrm{~g})(\mathrm{n}=32)$ were anesthetized with $4 \%$ isoflurane (ISO) for induction and maintained on 1.2-1.5\% of isoflurane in $70 \% \mathrm{~N}_{2} \mathrm{O}$ and $30 \% \mathrm{O}_{2}$ during surgery. Temperature probes were inserted into the rectum and core temperature was kept at $37.2 \pm 0.3^{\circ} \mathrm{C}^{\circ} \mathrm{C}$ with a blanket regulated by a homeothermic control unit. The tail artery was cannulated with a polyethylene catheter (PE-50) for the measurement of arterial blood 
pressure and arterial blood gasses. Mean arterial blood pressure was monitored continuously throughout the experiment. The animal was placed supine on a plastic holder and prepared for MCAO using the intraluminal filament model (Luckl et al., 2009). Briefly, the right common carotid artery (CCA) was carefully dissected from surrounding tissue and the right external carotid artery was ligated with a silk suture. A $0.39 \mathrm{~mm}$ silicone coated nylon filament (Doccol Corporation, Redlands, CA, USA) was inserted through the right CCA into the internal carotid artery and advanced until LD flowmetry indicated adequate MCA occlusion by a sharp decrease in blood flow. After 90 minutes of occlusion the filament was gently withdrawn and the reperfusion was monitored by LD for an additional 10 minutes.

\subsubsection{Head surgery}

The head of the animal was placed in a stereotaxic frame, a midline scalp incision was made and the skull exposed. A laser Doppler probe (tip diameter $1 \mathrm{~mm}$,fiber separation $0.25 \mathrm{~mm}$ ) attached to a flowmeter (PeriFlux 4001; Perimed, Stockholm, Sweden) was affixed over a 1 $\mathrm{mm}$-diameter circular area of thinned skull (4-5 mm lateral to midline, 1-2 mm posterior to Bregma). ECoG and DC potential were monitored using epidural silver chloride electrodes (4$5 \mathrm{~mm}$ lateral to midline, about $4 \mathrm{~mm}$ and $5 \mathrm{~mm}$ posterior to Bregma) overlying the territory of the right MCA. The electrodes and the LD probe were fixed to the skull with dental cement (Paladur; Heraeus, Germany). The reference electrode was placed under the skin in the nuchal region.

\subsubsection{Electrophysiological recordings}

The epidural electrodes were prepared from silver wire flamed to produce a $0.6-0.8 \mathrm{~mm}$ diameter spherical tips and then chloridized. The electrodes were placed in burr holes over the dura and connected to a differential amplifier (Jens Meyer, Munich, Germany). Analog-todigital conversion was performed using a Power 1401 (Cambridge Electronic Design Limited, Cambridge, UK). DC recordings were sampled at $200 \mathrm{~Hz}$ and the EEG activity was sampled at $5 \mathrm{kHz}$. 


\subsubsection{Coupling of spreading depolarization with PIFTs}

SDs were distinguished by a propagating large, negative DC shift. Coupling was expressed as the fraction of the total number of PIFTs and negative DC shifts.

\subsection{Hypothesis II.}

\subsubsection{Animal groups}

Adult male Sprague-Dawley rats $(\mathrm{n}=55)$, underwent 90-minute filament occlusion of the MCA followed by 72 hours of reperfusion. One group ( $n=32)$ was anesthetized with $1.2 \%$ isoflurane (ISO) and another group ( $\mathrm{n}=23)$ with $1.2 \%$ halothane (HALO).

\subsubsection{General surgery and filament occlusion}

The general surgery and the procedure of filament occlusion were performed similarly as we detailed earlier in 2.1.1.

\subsubsection{Laser Doppler Flowmetry}

CBF during ischemia $\left(0-90^{\text {th }} \mathrm{min}\right)$ and reperfusion $\left(0-10^{\text {th }} \mathrm{min}\right)$ was calculated as percentage of baseline prior to MCAO. The principles for identifying PIFTs have been defined previously based on LD recordings with two probes and the comparison of simultaneous LD and LS monitoring during filament MCAO in the rat (Luckl et al 2008; Luckl et al 2009): (a) flow transient with amplitude greater than $5 \%$ of pre-ischemic baseline; (b) duration of CBF changes longer than $60 \mathrm{~s}$; and (c) stable blood pressure during the event. Since the original description of the criteria for identifying PIFTs we observed in a few animals that the amplitudes of PIFTs can also be 3-4\% (lower than 5\%) in animals with intra-ischemic CBF less than $20 \%$. Likewise, a $3 \%$ amplitude as lowest threshold was noted in an early paper (Iijima et al., 1992). The recognition of the PIFTs was facilitated by the stereotypical morphology of the flow transients where five different morphologies of PIFTs in rats (Luckl et al., 2009). The peak-to-peak amplitude was calculated as the percent change in CBF relative to the baseline prior occlusion. 


\subsubsection{Infarct volume measurement}

Rats were sacrificed $72 \mathrm{~h}$ after MCAO. The brains were removed from the skull, cooled in ice cold saline for 20 minutes, and sectioned in the coronal plane at 2-mm intervals using a rodent brain matrix. The slices were incubated in phosphate buffered saline containing $2 \%$ 2,3,5triphenyltetrazolium chloride (TTC) at $37.0^{\circ} \mathrm{C}$ for 10 minutes. The TTC - stained sections were digitalized and the images were processed by using a computer based image analyzer (AIS 6.0; Imaging Research Inc., St. Catharines, ON, Canada). The damaged area was calculated by subtracting the area of the normal tissue in the hemisphere ipsilateral to the stroke from the area of the hemisphere contralateral to the stroke. Total lesion volumes in striatum and cortex were computed by summation of the infarct areas of 6 brain slices integrated by the thickness. An edema index was calculated from the total volume of the hemisphere ipsilateral to the occlusion and the total volume of the contralateral hemisphere (Yanamoto et al., 1996), a technique confirmed by a combined MRI imaging / water content study (Gerriets et al., 2004). The investigation was performed in a blinded fashion.

\subsection{Hypothesis III/a}

\subsubsection{General surgery and filament occlusion}

The general surgery and the procedure of filament occlusion $(n=10)$ were performed similarly as we detailed earlier in 2.1.1. The occlusion of the MCA was performed with the animal in the supine position in the stereotaxic frame. A $5 \times 5 \mathrm{~mm}$ area of the skull centered $5 \mathrm{~mm}$ lateral and $4 \mathrm{~mm}$ lateral to Bregma was thinned for LS imaging.

\subsubsection{Laser-speckle flowmetry: image acquisition and post-processing}

The thinned skull was illuminated by a collimated, laser diode (Hitachi, HL 785 1G, 785nm, 50mW, Thorlabs, Newton, NJ, U.S.A.) driven by a custom-made driver. One percent hydroxycellulose gel overlaid with cover glass was used to reduce the surface reflection from the thinned skull. The laser beam was adjusted to maintain homogeneous illumination of the surface of the skull. Images were taken by a 12-Bit, TEC cooled CCD camera (Uniq, Uniq Vision INC, USA) using imaging software (StreamPix, NorPix, Montreal, Quebec, Canada). The camera was externally triggered at $10 \mathrm{~Hz}$ using the digital output of an $\mathrm{A} / \mathrm{D}$ board 
(DataWave Technologies, Boulder, CO, U.S.A.) over the duration of MCAO. A 60-mm lens (Schneider-Kreuznach, Apo-Componon 2.8/40, Germany) was used to focus the image. The aperture was adjusted so the speckle size matched the pixel dimensions $(9.9 \mu \mathrm{m} \times 9.9 \mu \mathrm{m})$ and the exposure time for each frame was set to 1/120s. A 7 × 7 sliding window was employed to compute speckle contrast images from which CBF maps were extracted (Briers, 2001) as described previously (Dunn et al., 2001, Durduran et al., 2004). In this formulation, the correlation time $\left(\tau_{c}\right)$, which is inversely proportional to the mean velocity of the scattering particles, relates to the speckle contrast $(\mathrm{C})$ and the camera exposure time $(\mathrm{T})$ :

$$
C=\frac{\sigma}{\langle I\rangle}=\left[\frac{\tau_{c}}{2 T}\left(1-e^{\frac{-2 T}{\tau_{c}}}\right)\right]^{\frac{1}{2}}
$$

Relative changes in $\mathrm{CBF}$ are presumed to be proportional to the mean velocity. As reported by Wang et al (Wang et al., 2007), there are no significant differences in relative blood flow measurements using this formulation compared with the methods described by Goodman (Goodman, 1985) and (Bandyopadhyay et al., 2005). Ten CBF images were averaged to further improve the signal-to-noise ratio, resulting in an effective CBF frame rate of $1 \mathrm{~Hz}$. Relative CBF images were calculated by normalizing the $\mathrm{CBF}$ images with baseline measurements obtained at the beginning of the data collection with a correction for biological zero (CBF values when cerebral perfusion was zero) (Strong et al., 2006, Zhou et al., 2008). In this study biological zero images could not be acquired since the animals were not sacrificed immediately after the imaging. Thus, a separate group $(n=6)$ was used to define the biological zero value, which was found to be $8.2 \pm 1.4 \%$. Nine circular regions-of-interests (ROIs, $1 \mathrm{~mm}$ in diameter) (figure 1) were evenly placed on the images avoiding vessels for the analysis of PIFTs and CBF.

\subsubsection{The identification of PIFTs}

PIFTs were identified by their propagating characteristic: PIFT seen in at least two ROIs with appropriate time delay. The percentage of different morphologies of the PIFTs was calculated from the total number of PIFT over each ROI. The peak-to-peak amplitude was calculated as the percent change in $\mathrm{CBF}$ relative to the baseline prior occlusion. The hypoperfusive (negative) and hyperemic (positive) components of the amplitudes were also measured. 
A

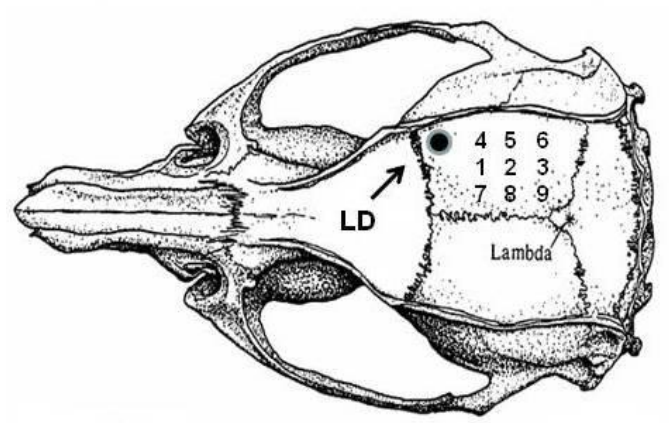

B

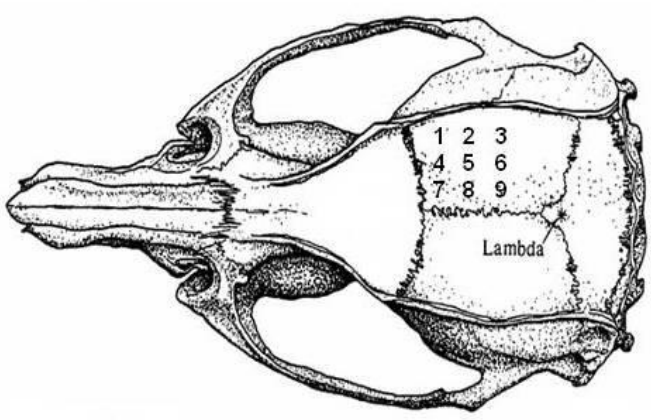

Figure 1. Schematic figure of the thinned skull with the positions of the nine (1-9) regions of interests (ROI) and the laser Doppler probe (LD) in the filament occlusion (panel A) and in the photochemically induced distal MCAO study (panel B).

\subsubsection{Laser Doppler Flowmetry}

A laser Doppler (LD) probe was placed over the ischemic cortex $5 \mathrm{~mm}$ lateral to Bregma (figure 1). We presumed that the simultaneous use of two laser methods may possible result in differences in flow measurement. However, in separate studies investigating the simultaneous use of LD and LS we have found that the LS yields a non-significant $(1.5 \pm 3 \%)$ higher flow if the LD laser is on, while the LS laser has no impact on the LD recordings. The criteria for identifying PIFTs with laser Doppler is detailed in 2.2.3.

\subsection{Hypothesis III/b}

\subsubsection{Photochemically induced distal middle cerebral artery occlusion}

Adult male Sprague-Dawley rats (290-320g) (n=8) were anesthetized with 4\% isoflurane for induction and maintained on 1.2-1.3\% isoflurane in $70 \% \mathrm{~N}_{2} \mathrm{O}$ and $30 \% \mathrm{O}_{2}$ during surgery and throughout the study. The right CCA was exposed by a ventral midline incision in the neck and the retraction of the sternocleidomastoid muscle. The exposed artery was surrounded by a snare. The rats were placed into a stereotaxic head holder, and a $6 \times 6 \mathrm{~mm}$ area centered $3 \mathrm{~mm}$ posterior and $4 \mathrm{~mm}$ lateral to Bregma was thinned for laser speckle (figure 1). Special attention was paid during surgical preparation to make the skull thickness uniform (Parthasarathy et al., 2008). A 2-cm vertical incision was made midway between the right eye and the right ear. The temporalis muscle was separated and retracted to expose the zygomatic 
and squamosal bones. Under an operating microscope (Carl Zeiss, Inc.), a burr hole of $4 \mathrm{~mm}$ in diameter was made with a high-speed drill $1 \mathrm{~mm}$ rostral to the anterior junction of the zygomatic and squamosal bones, revealing the distal segment of the middle cerebral artery. The epidural temperature was monitored by probe and maintained at $37.5 \pm 0.3^{\circ} \mathrm{C}$ with a custom-made air ventilator blowing warm air to the dura.

The right side of the stereotaxic frame was tilted upward for the imaging and so that the laser could hit the vessel perpendicularly. A laser beam was focused on the artery through a spherical lens of $25 \mathrm{~cm}$ focal length. To induce occlusion, a stock solution of Erythrosin B dye (MP Biomedicals, Solon, OH, USA), $17 \mathrm{mg} / \mathrm{mL}$ in $0.9 \%$ saline, was made for intravenous injection (via the tail vein) at a dose of $40 \mathrm{mg} / \mathrm{kg}$. Immediately after injection of the dye, the MCA was irradiated $(532 \mathrm{~nm})$ for 5 minutes with a $4 \mathrm{~mW}$ beam from a diode laser (LaserGlow Technologies, model LRS-0532-KFM-00030-03). A thrombus was produced proximally to the Y-shaped juncture of the frontal and parietal branches of the MCA by focusing the laser at that site. An orange fluorescence was immediately observed in the irradiated distal MCA segment under the operating microscope. A white thrombus began to form approximately 4-5 minutes later within the fluorescent segment and gradually elongated distally. Following the irradiation, the right CCA was occluded permanently by tightening the snare. Since real time speckle imaging was started immediately after the injection of the erythrosin B, we could confirm successful occlusion also by real time flow measurement. Changes in oxygenation and CBF were monitored through a thinned skull preparation with intrinsic optical imaging (Grinvald et al., 1986, Kohl et al., 2000) and speckle contrast imaging (Briers 2001; Dunn et al 2001; Durduran et al 2004).

\subsubsection{Image acquisition}

Although we monitored CBF with LS as well as oxygenation with intrinsic optical imaging in the original study (Luckl et al., 2010), only the CBF data are used in the present analysis. For speckle imaging, a collimated laser diode (DL7140-201S, $785 \mathrm{~nm}, 80 \mathrm{~mW}$; Thorlabs, Newton, NJ) driven by a commercial laser diode controller (LDC 500; Thorlabs, Newton, NJ) provided uniform illumination on the thinned skull surface. To acquire spectral images at multiple-wavelengths, a xenon arc lamp (XBO $150 \mathrm{~W} / 1$ OFR; OSRAM) was directed through 
an 8-position filter wheel (FW-1000, Applied Scientific Instrumentation, Inc) and then coupled to a 12-mm fiber bundle illuminating the cortex. The filter wheel was programmed such that external trigger pulses consecutively switched the filter wheel between four positions. Three positions contained 10-nm band-pass filters centered at wavelengths of 540, 580, and $610 \mathrm{~nm}$, with the other position blocked. The laser diode was off while the filter wheel was in the first three positions, but switched on when the filter wheel reached the blocked position, enabling interleaved spectral and speckle imaging with $140 \mu \mathrm{m}$ spatial resolution. Every 2 seconds, 3 spectral and 15 speckle images were taken.

We used the same camera, lens and imaging software as detailed in 2.3.2. Biological zero images could not be obtained because the animals were not sacrificed immediately after the imaging. Therefore, a group of animals $(n=6)$ was used to determine the biological zero value, which was found to be $9.1 \pm 1.2 \%$ of baseline.

\subsubsection{Temporal protocol and Image analysis}

After five minutes of collecting baseline flow and oxygenation data, a 15 minute data collection of real time speckle was initiated synchronously with the production of photothrombosis in order to confirm a successful occlusion. The occlusion usually occurred in the 4-5th minute of the real time speckle sequence. In the remaining 10 minutes CBF was monitored to exclude the chance of spontaneous reperfusion. After confirming the successful, reperfusion-free occlusion, surface blood flow and oxygenation were monitored in 15 min. long intra-ischemic sequences over a period of two hours. The high spatial resolution images were divided into 9 equal sectors, and one circular region of interest (ROI, $0.3 \mathrm{~mm}$ in diameter; figure 1) was placed in each sector, where care was taken to ensure the ROIs were not over any large blood vessels. Changes in blood flow in each ROI over time were analyzed. The average residual CBF during the first 120 min of ischemia was calculated as a percentage of the baseline (5 min.) prior to the occlusion over each ROI. PIFTs were identified by their propagating feature (transients seen in at least two ROIs with appropriate time delay). The amplitude was obtained as the percent change in CBF. We measured the hypoperfusion and hyperemia components of the amplitudes separately. 


\subsubsection{Infarct volume measurement}

Rats were sacrificed 24 hours after MCAO. The brain was removed from the skull and was sectioned in the coronal plane at $1.5 \mathrm{~mm}$ intervals using a rodent brain matrix. The brain slices were stained with $2 \%$ TTC, photographed and the infarct volume was determined as described previously (Luckl et al 2008). We also mapped the infarcted area to the imaging data. According to our sectioning method slices from No. 2 to No. 5 correspond to the thinned area on the skull. The distance between the midline and the border of the infarct zone on the TTC slices was measured and mapped onto the flow and hemoglobin images.

\subsection{Statistical analysis}

Changes in the physiological parameters (baseline and intra-ischemic) were tested using a paired t-test in each study.

Significant differences in the flow parameters and outcome between anesthetic groups were examined with a two-sample t-test (unpaired) in the filament occlusion study. Animal groups were determined in a scatter plot based on presence or absence of a substantial cortical infarct. Analyses were accomplished using the R Software Environment. Statistical models for single markers as well as for combinations were analyzed using binomial logistic regression (developing a severe cortical infarct - defined as having an infarct size $>80 \mathrm{~mm}^{2}-$ used as the response variable). For a single marker, this yields a precise (with respect to the presented data) point to discriminate between animals with ("ci") and without ("no") severe cortical infarct. All data greater (or lower, depending on actual results) than that point would be predicted as "ci"; all other data as "no". The number of correctly predicted animals (CPA) was calculated based on the discrimination point in order to compare the predictability of the different markers. This model will predict data with more confidence the greater the distance between the data and the discrimination point. With the application of this technique we can determine borders beyond which the model would predict animals with at least $95 \%$ certainty. This is only achievable, however, if the discrimination is "imperfect", i.e. if there are some incorrectly predicted animal, otherwise the model cannot calculate probabilities of errors. This analysis is valid for combinations of two markers, also, except that the model discriminates based on a line, not a single point. Whether or not adding another parameter (two-fold 
combination versus three-fold combination) to a model is beneficial was calculated using the likelihood ratio test.

Furthermore, we put all of the data into a matrix in order to find further relations between outcome and CBF parameters in this large animal pool. Correlations between PIFT parameters, residual $\mathrm{CBF}$ and outcome were assessed using Spearman analysis both separately in the HALO and ISO groups as well as in the combined group (ISO+HALO) of animals. Regression analysis was not corrected for multiple testing. Statistical significance was considered when $\mathrm{p}<0.05$ and all data are expressed as mean \pm standard deviation.

A 2-way ANOVA analysis was performed to statistically test for differences in blood flow between ROIs during ischemia and any regional differences in distribution of PIFT types in each LS study. The mean amplitudes (positive, negative, peak to peak) of the PIFTs over the penumbra (ROI 1,2,3 and ROI 4,5,6) and the peri-ischemic area (ROI 7,8,9) were tested also for significant differences (penumbra vs peri-ischemic area) with a two sample t-test in both studies.

\section{RESULTS}

All of the physiological variables were within normal limits both during the surgical preparation and during focal ischemia in each animal of every experiment. We excluded three animals from the DC-PIFT coupling study (hypothesis I) and six animals from the post-hoc analysis of the filament occluded animals (hypothesis II) due to an inadequate quality (non evaluable) of DC recordings or LD flowmetry. Similarly, 1-1 animals were not included in the LS studies (hypothesis III/a, and III/b) because of the poor quality of the optical imaging data.

\subsection{Hypothesis I.}

We collected 46 spreading depolarizations and 41 PIFTs time coupled (coupling rate 89\%) in the filament occluded animals $(n=12)$ (figure2). The coupling rate was $76 \%$ in animals with intra-ischemic flow lower than $20 \%$ of baseline and $97 \%$ if the flow remained above $20 \%$ of baseline. 
Collecting 20 more animals with the same experimental setup in another study (not published) and adding to the original animal pool $(n=32)$ we could calculate a coupling rate of $93 \%$.
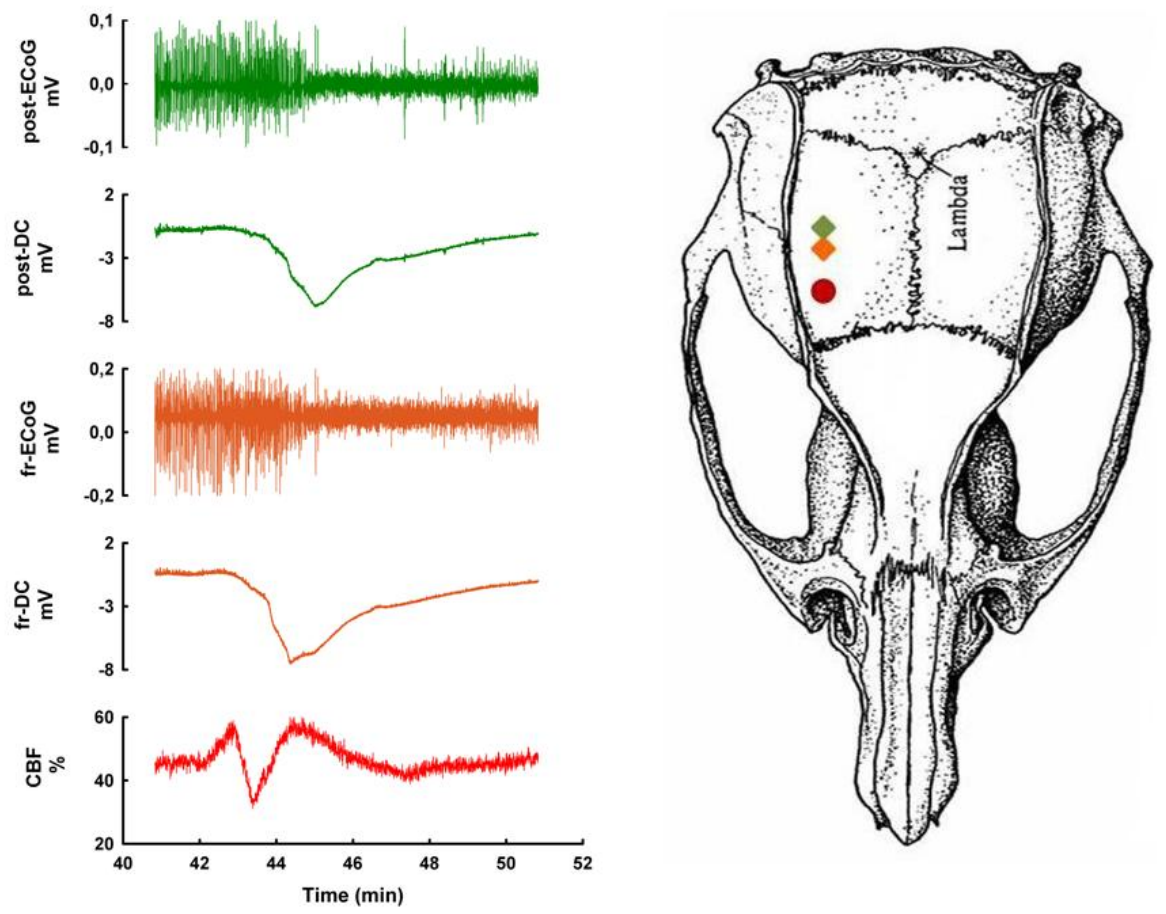

Figure 2. Epidural DC, ECoG and CBF monitoring during filament occlusion. The two silver chloride electrodes (diamond symbols) (frontal (fr) and posterior (post)) were placed epidurally two mm caudal to the laser Doppler probe (closed circle) (4-5 lateral, and 1-2 mm posterior to Bregma).

\subsection{Hypothesis II.}

\subsubsection{PIFT parameters and outcome}

The histology showed a bimodal outcome. Lesion in the basal ganglia and in the cortex (mean of $130-140 \mathrm{~mm}^{3}$ but never less than $89 \mathrm{~mm}^{3}$ ) developed in 39 animals $(71 \%)$. The remainder of the animals $(n=16)$ showed only a small or negligible cortical infarct, while the basal ganglia were variably affected by the injury (table 1, figure 3). Table 1 presents the mean residual CBF, the reperfusion, the parameters of the PIFTs (mean number, amplitude) and the outcome (infarct size, edema) in different anesthetic groups. 
These parameters were also calculated in subgroups containing animals either with substantial cortical infarcts (ci) or with only a small or negligible cortical infarct (no). Statistical analyses showed that both the number of PIFTs and the level of reperfusion is significantly higher in the "ci" groups but the significance level is considered only marginal $(p<0.05)$ with the latter marker (table 1).

\begin{tabular}{|c|c|c|c|c|c|c|c|}
\hline \multirow[t]{2}{*}{ Anesthesia } & \multicolumn{2}{|c|}{ Cerebral blood flow } & \multicolumn{2}{|c|}{ Flow transients } & \multicolumn{3}{|c|}{ Infarct size $\left(\mathrm{mm}^{3}\right)$} \\
\hline & $\mathrm{CBF}$ & Reperfusion & Number & Amplitude & BG & Cortex & Total \\
\hline $\begin{array}{l}\text { ISO (ci) } \\
(\mathrm{n}=25)\end{array}$ & $35 \pm 12$ & $134 \pm 53$ & $6.1 \pm 2.5$ & $14 \pm 9.7$ & $57 \pm 10$ & $129 \pm 25$ & $186 \pm 29$ \\
\hline $\begin{array}{c}\text { ISO (no) } \\
(n=7)\end{array}$ & $47 \pm 16$ & $87 \pm 30^{*}$ & $3.3 \pm 1.7^{* *}$ & $19 \pm 7.9$ & $44 \pm 19^{*}$ & $8 \pm 8^{* *}$ & $52 \pm 24^{* *}$ \\
\hline $\begin{array}{c}\text { HALO (ci) } \\
(\mathrm{n}=14)\end{array}$ & $40 \pm 13$ & $131 \pm 31$ & $7.4 \pm 3.8$ & $14 \pm 7.7$ & $58 \pm 10$ & $137 \pm 37$ & $195 \pm 39$ \\
\hline $\begin{array}{c}\text { HALO (no) } \\
(n=9)\end{array}$ & $45 \pm 13$ & $103 \pm 25^{*}$ & $3.8 \pm 1.4^{\star *}$ & $18 \pm 3.6$ & $38 \pm 15^{\star *}$ & $13 \pm 12^{\star *}$ & $51 \pm 16^{\star *}$ \\
\hline
\end{tabular}

ISO=isoflurane, HALO=halothane, ci=substantial cortical infarct, no=small or negligible cortical infarct, $\mathrm{BG}=$ basal ganglia. *= Significant difference $(\mathrm{p}<0.05)$ between the "ci" and "no" subgroup in the same anesthetic groups. **= Significant difference $(\mathrm{p}<0.01)$ between the "ci" and "no" subgroup in the same anesthetic groups. Data expressed as mean \pm SD 
A

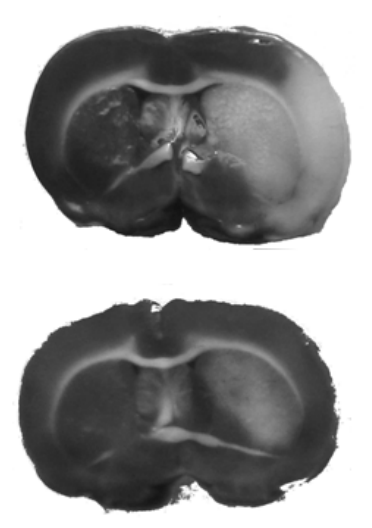

B

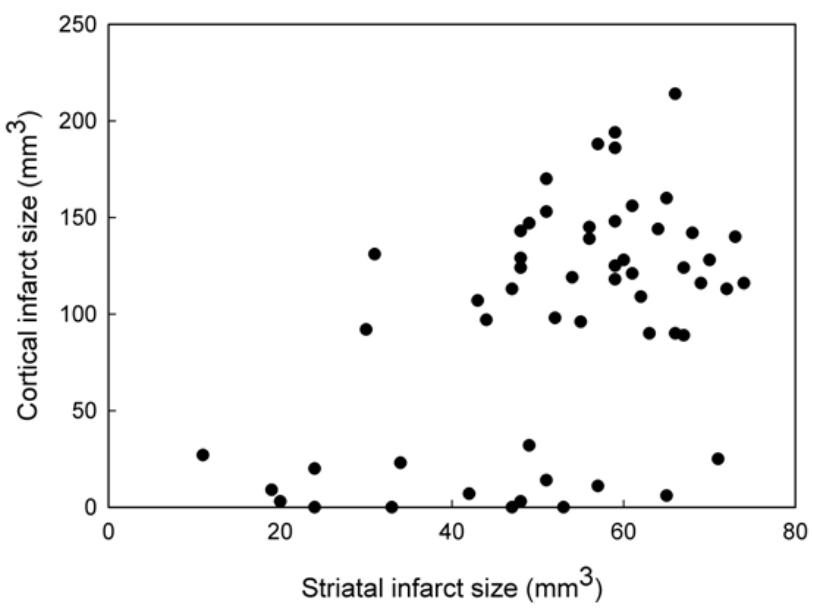

Figure 3. The bimodal distribution of the cortical infarct volume. A: TTC stained sections from an animal with substantial cortical infarct (upper image) and from an animal with no cortical infarct (lower image). B: The bimodal, histological outcome in all (ISO+HALO) of the filament occluded animals.

\subsubsection{Logistic regression analyses of single parameters}

The results of the regression analyses are detailed in table 2. The analyses revealed that the most accurate, single marker is the number of PIFTs in each anesthetic subgroup. 45 out of 55 animals can be predicted correctly with the discrimination point of 3.8 in the combined anesthetic group. It is important to note that setting that discrimination point beyond the range of the data would still result in 39/55 correctly predicted animals in the combined anesthetic group as a "worst case". The number of CPA with other markers such as CBF, reperfusion and amplitudes are frequently close to that worst case; thus these markers are essentially not helpful in the prediction of the histological outcome. In fact, the discrimination point for the amplitude in the ISO group (41\%) is beyond the range (4-39\%). 
Table 2. Logistic regression analysis of single markers in different anesthetic groups

\begin{tabular}{|c|c|c|c|c|c|c|}
\hline Anesthesia & $\begin{array}{c}\text { Flow } \\
\text { parameters }\end{array}$ & Range & $\begin{array}{l}\text { Discrimination } \\
\text { point }\end{array}$ & $\begin{array}{l}\text { Lower } \\
\text { border }\end{array}$ & $\begin{array}{l}\text { Upper } \\
\text { border }\end{array}$ & $\begin{array}{c}\text { Ratio of } \\
\text { CPA to } \\
\text { total } \\
\text { number }\end{array}$ \\
\hline \multirow{4}{*}{ ISO } & CBF \% & $9-74$ & 62 & 12 & 112 & $26 / 32$ \\
\hline & No. of PIFTs & $1-12$ & 2.8 & -1.2 & 6.8 & $27 / 32$ \\
\hline & Reperfusion \% & $65-302$ & 75 & 6 & 144 & $26 / 32$ \\
\hline & Amplitude \% & $4-39$ & 41 & -15 & 98 & $25 / 32$ \\
\hline \multirow{4}{*}{ HALO } & CBF \% & $17-76$ & 56 & -36 & 149 & $14 / 23$ \\
\hline & No. of PIFTs & $2-10$ & 5.1 & 2.6 & 7.6 & $20 / 23$ \\
\hline & Reperfusion \% & $67-196$ & 103 & 21 & 186 & $17 / 23$ \\
\hline & Amplitude \% & $5-37$ & 20 & -9 & 49 & $15 / 23$ \\
\hline \multirow{4}{*}{ ISO+HALO } & CBF \% & $9-76$ & 59 & 0 & 118 & $41 / 55$ \\
\hline & No. of PIFTs & $1-12$ & 3.8 & 0.2 & 7.4 & $45 / 55$ \\
\hline & Reperfusion \% & $65-302$ & 85 & -1 & 171 & $41 / 55$ \\
\hline & Amplitude \% & $4-39$ & 31 & -18 & 80 & $36 / 55$ \\
\hline
\end{tabular}

Discrimination point distinguishes between animals with and without substantial cortical infarct. Borders are values beyond which the model would predict an animal with at least $95 \%$ certainty. CBF, amplitude and reperfusion are expressed as percent of baseline prior to MCA occlusion. $\mathrm{CPA}=$ correctly predicted animals.

\subsubsection{Logistic regression analyses of combinations of parameters}

The results of the regression analyses (6 combinations) in all animals are summarized in figure 4. The results reveal that the combination of CBF and number of PIFT gives the best prediction in two-fold combinations in the combined anesthetic subgroup. The combination of CBF and PIFT is the best predictor similarly both in the halothane (CPA: 20/23) and the isoflurane subgroups (CPA: 31/32). The results suggest that the perfusion deficit is an important co-factor in the prediction of outcome: a higher intra-ischemic flow requires more PIFTs for the development of a substantial cortical infarct (figure 4, 5). At least 3-4 PIFTs 
have to develop even in severe ischemia (flow of 20-30\%) in order to see a substantial cortical infarct after 72 hours. The likelihood-ratio test did not reveal a significant benefit comparing the best two-fold (CBF/number of PIFTs) combination and the variations of the three-fold combinations (CBF/number of PIFTs/Amplitudes; $\mathrm{D}=2.158, \mathrm{p}=0.14)(\mathrm{CBF} / \mathrm{number}$ of PIFTs/Reperfusion; $\mathrm{D}=0.00062, \mathrm{p}=0.98)$ ).
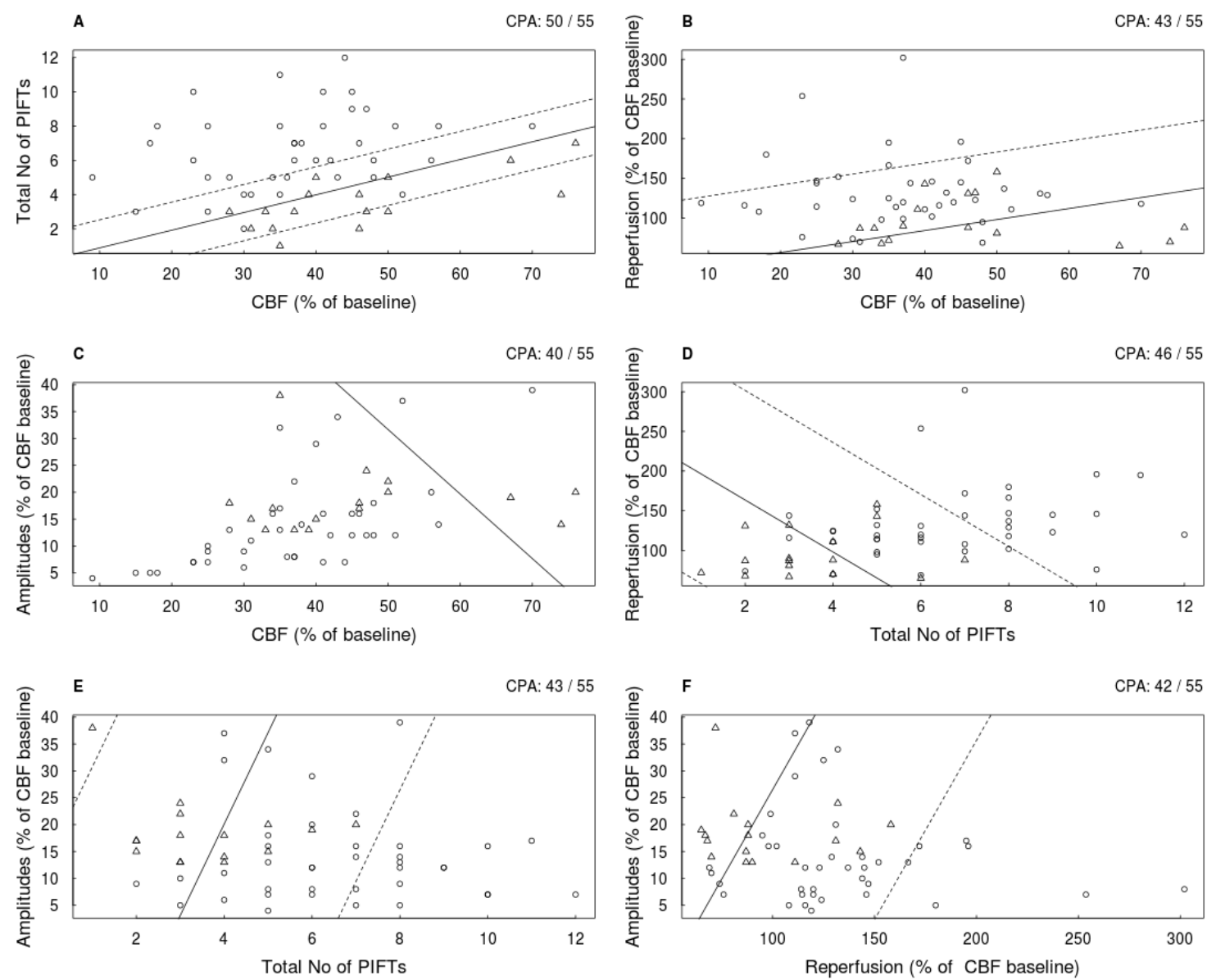

Figure 4. The results of logistic regression analysis in all (ISO+HALO) of the filament occluded animals using two explanatory variables. Open circles designate animals with substantial, cortical infarct size (ci), and the triangles indicate animals with negligible cortical infarcts (no) in all panels (A-F). The solid lines distinguish "ci" and "no" according to the logistic regression. For example, in panel "A" all animals above the solid line were predicted as "ci", and all animals below it as "no". Note that in panel "A" three triangles are above the solid line and two circles are below it, thus $\mathrm{CPA}=50 / 55$. The dashed lines symbolize the borders, beyond which the model will predict with at least 95\% certainty, for the "ci" and the "no" animals, and if those limits are broad the dashed line may not be visible (Panel C). The CPA is indicated in the upper right corner of each panel. 

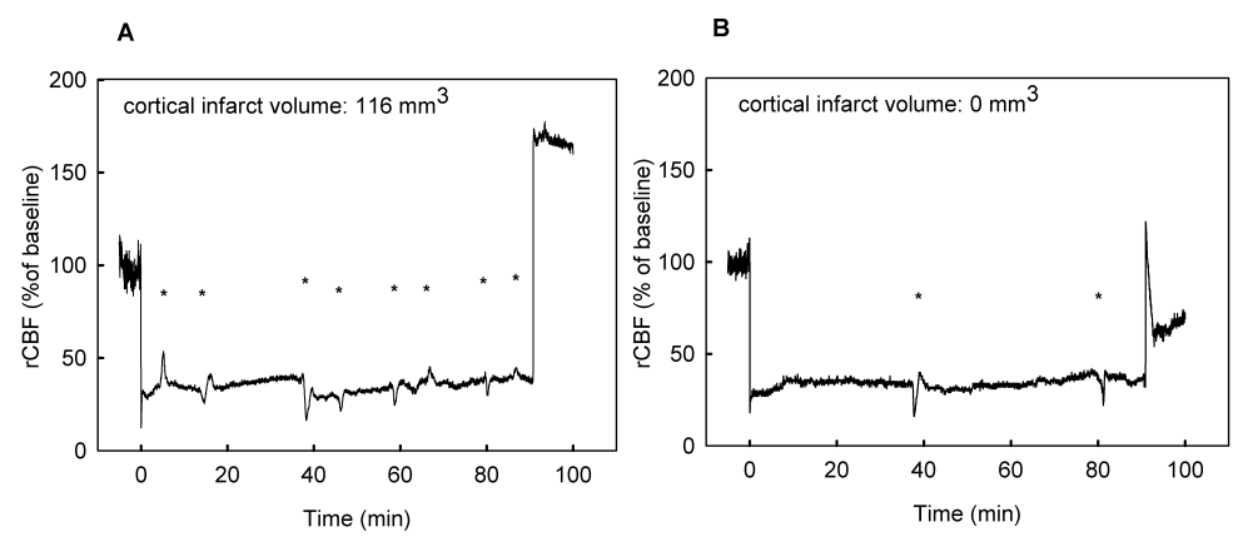

C

D
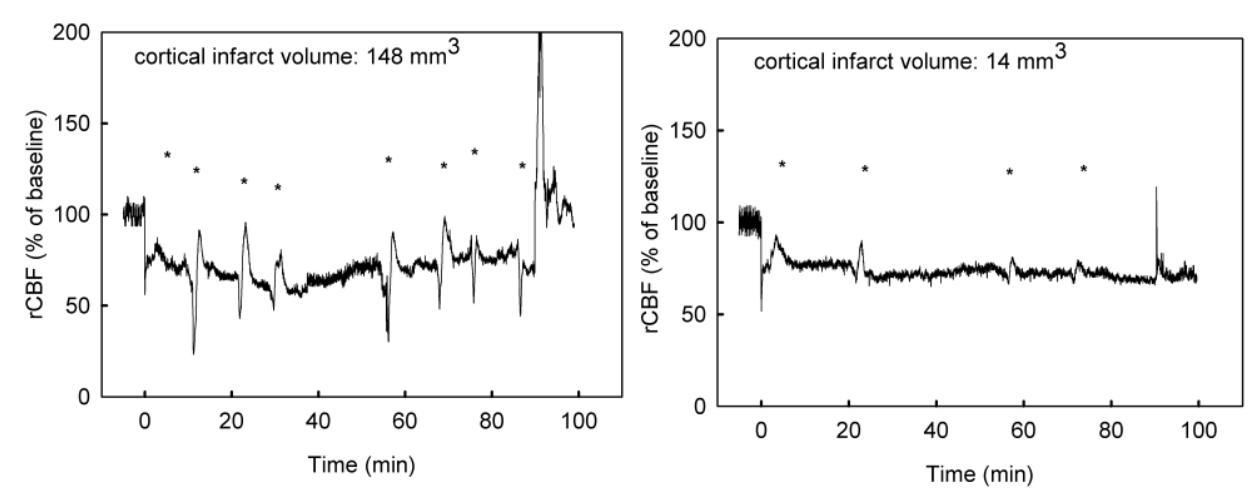

Figure 5. Four representative flow time-courses. Panel "A" and "B" show flow traces from animals with low intra-ischemic flow (30\%). The animal in panel "A" developed eight PIFTs and large infarct $\left(116 \mathrm{~mm}^{3}\right)$ while the animal in panel "B" is devoid of the sufficient number of PIFTs and therefore did not develop a cortical infarct. Panel "C" and "D" demonstrates animals with high intra-ischemic (70\%) flow. Despite a relatively high CBF, the animal in panel "C" had eight PIFTs and showed a substantial cortical infarct $\left(148 \mathrm{~mm}^{3}\right)$, while animal in panel "D" with four transients developed only a negligible cortical infarct $\left(14 \mathrm{~mm}^{3}\right)$. Asterisks represent flow transients in each panel.

\subsubsection{Spearman analysis}

The Spearman correlation analyses (table 3) were completed both in the anesthetic subgroups (ISO, HALO) as well in the combined group of animals. We found four correlations which are common in each group (ISO, HALO, ISO+HALO) and linked to flow parameters: The number of PIFTs is positively correlated with cortical infarct, and the degree of edema. The amplitude of the PIFTs is inversely correlated with the cortical infarct. Mean intra-ischemic flow shows a positive correlation with the mean amplitude of the PIFTs. It is important to mention that the results of the Spearman analysis should be treated carefully, since we did not 
correct the significance level. Therefore, we present the raw data (correlations) between the measured flow parameters and the cortical infarct size (histological outcome) in a separate figure (figure 6.).
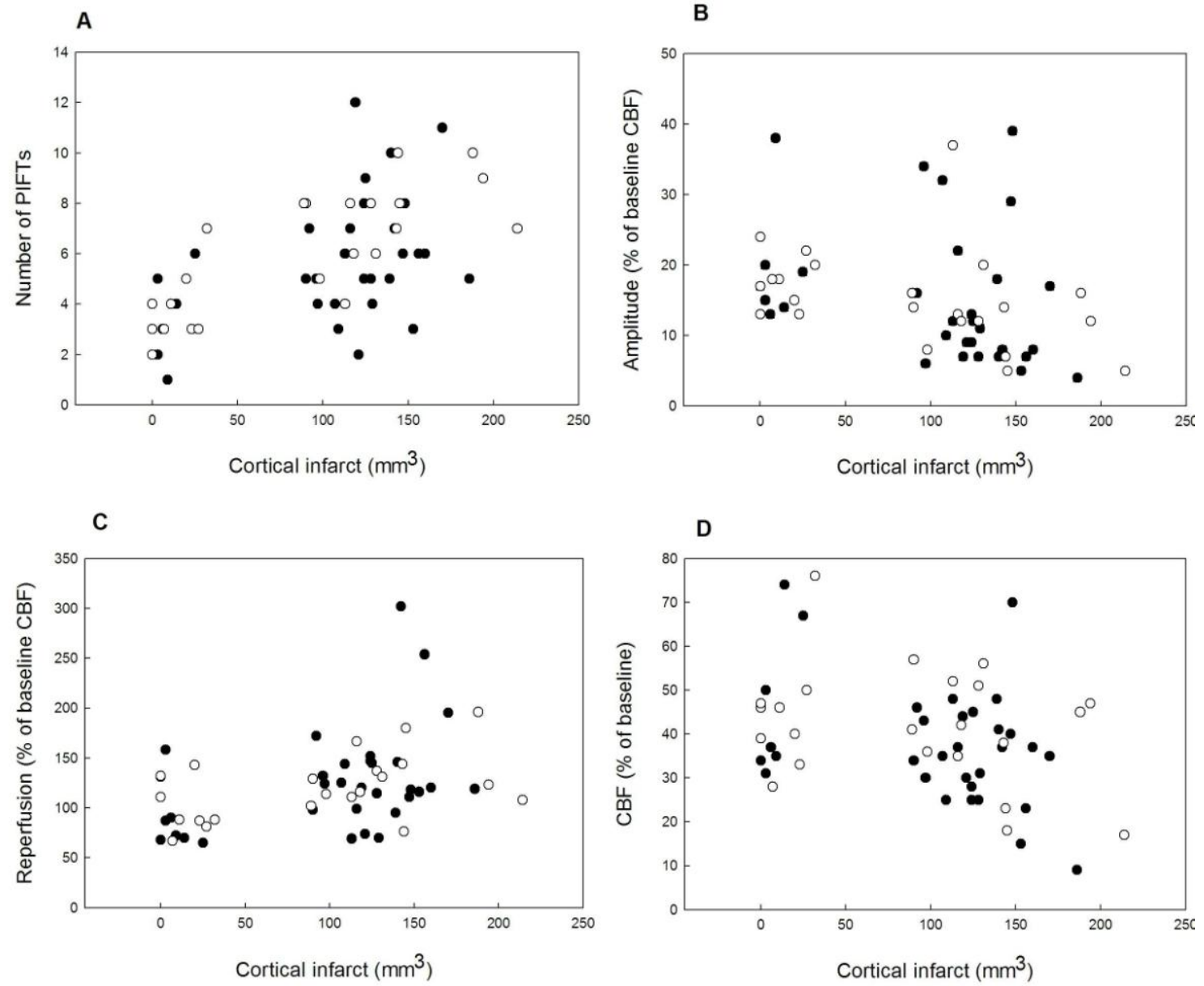

Figure 6. Relationships (raw data) between the measured flow parameters (number and amplitude of PIFTs, intraischemic $\mathrm{CBF}$, reperfusion) and the cortical infarct size in individual charts (panel A, B, C, D). Closed circles symbolize the ISO while the open circles designate the HALO animals. 


\begin{tabular}{|c|c|c|c|c|c|c|}
\hline Table 3. & $\begin{array}{c}\text { Intra- } \\
\text { ischemic } \\
\text { CBF }\end{array}$ & & & & & \\
\hline $\begin{array}{l}\text { Number of } \\
\text { PIFTs }\end{array}$ & $\bullet+$ & $\begin{array}{l}\text { Number of } \\
\text { PIFTs }\end{array}$ & & & & \\
\hline Amplitude & $\begin{array}{c}\leftrightarrow+ \\
\bullet \bullet+ \\
\square \square+\end{array}$ & $\bullet-$ & Amplitude & & & \\
\hline $\begin{array}{c}\text { Infarct } \\
\text { basal ggl. }\end{array}$ & NS & $\begin{array}{l}\bullet \bullet \bullet+ \\
\square+\end{array}$ & $\bullet \bullet-$ & $\begin{array}{c}\text { Infarct } \\
\text { basal ggl. }\end{array}$ & & \\
\hline Infarct cortex & NS & $\begin{array}{l}\bullet+ \\
\bullet \bullet \bullet+ \\
\bullet \square+\end{array}$ & $\begin{array}{l}\bullet- \\
\bullet \bullet- \\
\bullet-\end{array}$ & $\begin{array}{c}\bullet+ \\
\square+\end{array}$ & Infarct cortex & \\
\hline Edema & NS & $\begin{array}{l}\bullet+ \\
\bullet \bullet+ \\
\square+\end{array}$ & $\bullet \bullet-$ & $\begin{array}{l}\bullet+ \\
-+\end{array}$ & $\begin{array}{c}\bullet++ \\
\bullet \bullet+ \\
\square+ \\
\square+\end{array}$ & Edema \\
\hline Reperfusion & NS & $+4+$ & NS & $\bullet+$ & $\begin{array}{c}+ \\
\square+\end{array}$ & $\stackrel{\bullet+}{\bullet+}$ \\
\hline
\end{tabular}

Spearmann analysis in the isoflurane $(\bullet)$, halothane $(\bullet)$, and combined $(\boldsymbol{\square})$ group.

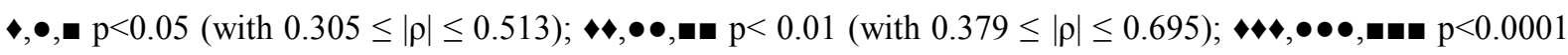
(with $0.578 \leq|\rho| \leq 0.962$ ); NS. non significant; + positive correlation; - negative correlation

\subsection{Hypothesis III/a.}

The CBF averaged over the 90 minutes of ischemia ranged between 36 and $54 \%$ by LS over the nine ROIs. The reperfusion was complete in each animal. The mean CBF in the medial row (ROI 7-9: 47-54\%) was statistically higher ( $<$ 0.001) than the flow both in the middle (ROI 1-3: 38-39\%) and lateral row (ROI 4-6: 36-42\%) but we could not observe anteriorposterior heterogeneity in ischemic flow. We presume that ROI 7-9 with higher CBF (watershed zone between ACM and anterior cerebral artery (ACA)) and without infarcts represents the peri-ischemic area. The mean number of PIFTs counted with LS was $4.6 \pm 1.8 / 90 \mathrm{~min}$.

\subsubsection{Morphology of PIFTs}

We could distinguish five different morphologies of flow transients by LS (figure 7): I.monophasic, hyperemic; II.-III. biphasic (hyperemia or hypoperfusion dominant); 
IV.-V. monophasic, hypoperfusive (transient or prolonged). There were 396 events in the nine ROIs (10 animals) over 90 minutes of ischemia.

\section{Monophasic, hyperemic flow transients}

The hyperemic flow changes represent $45.7 \%$ (181/396) of all events. This type of flow transient is typical for the parasagittal ribbon (peri-ischemic area) of the cortex where its occurrence is $55-64 \%$ (table 4, figure 7, 8). The occurrence of type I was higher in this region than in areas more lateral ( $\mathrm{p}<0.01$ ). The mean flow values were $47 \pm 11 \%, 50 \pm 10 \%$, and 54 $\pm 14 \%$ of baseline over these ROIs.
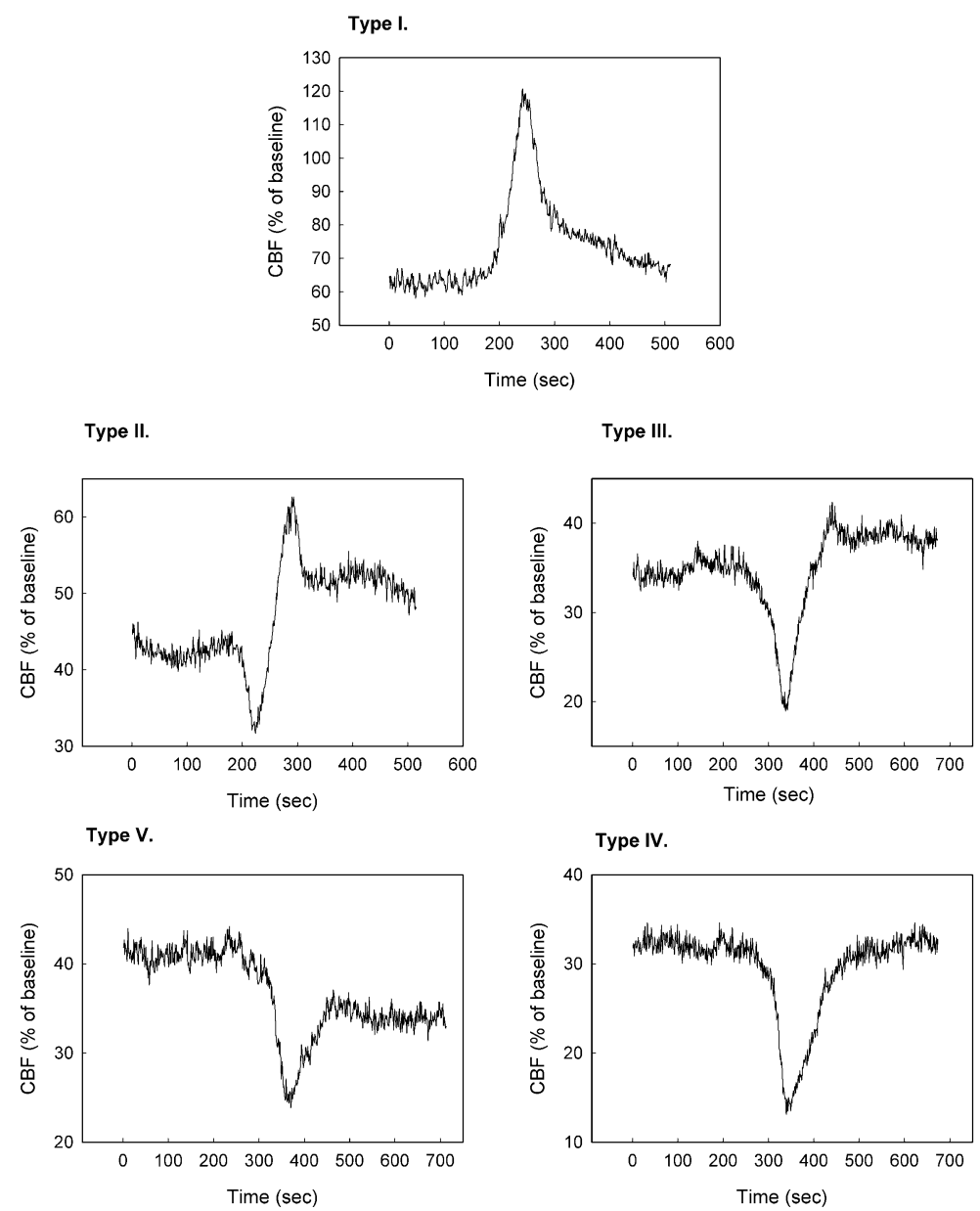

Figure 7. The figure presents five different morphological variants of the flow transients. The residual CBF are shown to the left and the elapsed time at the bottom of each panel. 


\section{II-III. Biphasic flow transients}

The 33.3\% (132/396) of all events are biphasic (figure 7,8). The first component of a biphasic transient is always hypoperfusion followed by hyperemia. During ischemia, this type of flow transient seems to appear evenly over the entire monitored cortex (table 4). We distinguished both hyperemia (II) and hypoperfusion (III) dominant forms based on whether the flow increase or the decrease contributed more than $50 \%$ to the amplitude. The occurrence of type III is higher in the penumbra than peri-ischemic area $(\mathrm{p}<0.01)$. We did not find significant differences in the mean pre-transient CBF between these two subgroups $(43 \pm 15 \%$ (II) vs $41 \pm 12 \%$ (III), t-test $\mathrm{p}=0.37$ ).
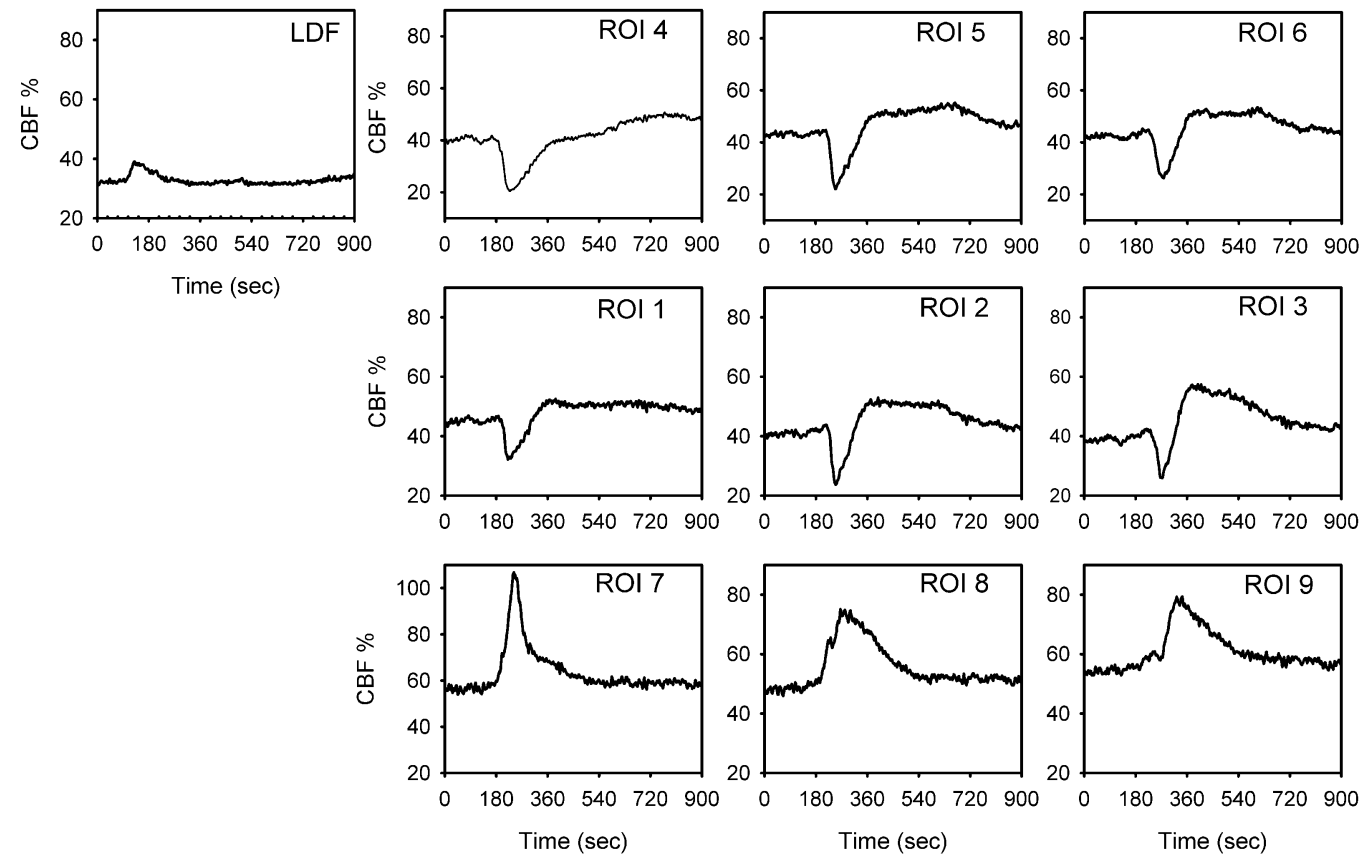

Figure 8. The illustration of spatial heterogeneity of a propagating peri-infarct flow transient (PIFT). Each panel shows the change in CBF (\% of baseline) over the nine ROIs as well as from the laser Doppler site (see figure 1). While the peri-ischemic area is predominated by hyperemic flow changes with larger amplitude, the hypoperfusive (type IV) and hypoperfusion dominant biphasic flow changes (type III) are typical for the lateral regions.

\section{$I V$-V. Monophasic, hypoperfusive flow transients}

A drop in perfusion associated with a propagating event, but not followed by relative hyperemia was most common (16-31\%) in the antero-lateral part of the MCA territory (ROI 
$1,2,4,5$ ) (figure 7, 8). Blood flow is restored in 2-3 min. in type IV, while there is no full flow recovery in type V. The hypoperfusive flow changes (type IV and V) represent only $14.9 \%$ (59/396) of all events. Interestingly, this value is $31 \%$ in ROI 4 (the closest point to LD), much higher than that seen with LD (10.9\%). The occurrence of type IV and V was greater over the lateral row than over the most medial row (ROI 7-9) $(\mathrm{p}<0.01)$. Hypoperfusive flow transients were found in 9 of 10 animals, but in two of these animals the subsequent flow transients were hyperemic over the same region of interest, so the appearance of type IV-V was "reversible".

\begin{tabular}{|c|c|c|c|c|c|c|c|c|}
\hline \multicolumn{2}{|l|}{$\overline{\mathrm{ROI}} 4$} & \multicolumn{3}{|c|}{ ROI 5} & \multicolumn{3}{|c|}{ ROI 6} & \multirow[b]{2}{*}{$\%$} \\
\hline Type & Number & $\%$ & Type & Number & $\%$ & Type & Number & \\
\hline I & 17 & 43 & I & 13 & 33 & I & 19 & 46 \\
\hline II & 5 & 13 & II & 8 & 20 & II & 10 & 24 \\
\hline III & 4 & 10 & III & 7 & 18 & III & 7 & 17 \\
\hline IV & 5 & 13 & IV & 6 & 15 & IV & 2 & 5 \\
\hline v & 9 & 23 & v & 6 & 15 & v & 3 & 7 \\
\hline ROI 1 & & & ROI 2 & & & ROI 3 & & \\
\hline Type & Number & $\%$ & Type & Number & $\%$ & Type & Number & $\%$ \\
\hline I & 13 & 33 & I & 17 & 43 & I & 22 & 52 \\
\hline II & 10 & 25 & II & 7 & 18 & II & 9 & 21 \\
\hline III & 9 & 23 & III & 9 & 23 & III & 8 & 19 \\
\hline IV & 5 & 13 & IV & 3 & 8 & IV & 3 & 7 \\
\hline v & 3 & 8 & v & 4 & 10 & v & 0 & 0 \\
\hline ROI 7 & & & ROI 8 & & & ROI 9 & & \\
\hline Type & Number & $\%$ & Type & Number & $\%$ & Type & Number & $\%$ \\
\hline I & 24 & 56 & $I$ & 28 & 64 & I & 28 & 67 \\
\hline II & 12 & 28 & II & 9 & 20 & II & 8 & 19 \\
\hline III & 3 & 7 & III & 4 & 9 & III & 3 & 7 \\
\hline IV & 4 & 9 & IV & 3 & 7 & IV & 3 & 7 \\
\hline v & 0 & 0 & v & 0 & 0 & v & 0 & 0 \\
\hline
\end{tabular}




\subsubsection{Amplitudes of PIFTs}

Both the peak to peak $(\mathrm{p}<0.01)$ and the positive $(\mathrm{p}=0.01)$ amplitudes of the PIFTs were higher over the peri-ischemic (ROI 7-9) versus penumbral (ROI 1-3) area.

\begin{tabular}{|c|c|c|c|c|c|c|c|c|c|}
\hline $\begin{array}{c}\text { Filament } \\
\text { Occlusion }\end{array}$ & positive & negative & $p$ to $p$ & positive & negative & $p$ to $p$ & positive & negative & $p$ to $p$ \\
\hline \multirow[t]{2}{*}{ Penumbra } & \multicolumn{3}{|c|}{ ROI 1} & \multicolumn{3}{|c|}{ ROI 2} & \multicolumn{3}{|c|}{ ROI 3} \\
\hline & $8 \pm 4$ & $6 \pm 3$ & $14 \pm 14$ & $8 \pm 3$ & $7 \pm 4$ & $15 \pm 5$ & $10 \pm 5$ & $6 \pm 5$ & $16 \pm 7$ \\
\hline \multirow{2}{*}{$\begin{array}{c}\text { Peri- } \\
\text { ischemic } \\
\text { area }\end{array}$} & \multicolumn{3}{|c|}{ ROI 7} & \multicolumn{3}{|c|}{ ROI 8} & \multicolumn{3}{|c|}{ ROI 9} \\
\hline & $17 \pm 16$ & $4 \pm 4$ & $22 \pm 14$ & $17 \pm 11$ & $5 \pm 5$ & $22 \pm 10$ & $19 \pm 10$ & $4 \pm 4$ & $23 \pm 8$ \\
\hline $\begin{array}{l}\text { Distal } \\
\text { MCAO }\end{array}$ & positive & negative & $p$ to $p$ & positive & negative & $p$ to $p$ & positive & negative & $p$ to $p$ \\
\hline \multirow[t]{2}{*}{ Penumbra } & \multicolumn{3}{|c|}{ ROI 4} & \multicolumn{3}{|c|}{ ROI 5} & \multicolumn{3}{|c|}{ ROI 6} \\
\hline & $11 \pm 12$ & $8 \pm 9$ & $19 \pm 19$ & $6 \pm 3$ & $7 \pm 6$ & $13 \pm 5$ & $12 \pm 9$ & $7 \pm 7$ & $19 \pm 14$ \\
\hline \multirow{2}{*}{$\begin{array}{c}\text { Peri- } \\
\text { ischemic } \\
\text { area }\end{array}$} & \multicolumn{3}{|c|}{ ROI 7} & \multicolumn{3}{|c|}{ ROI 8} & \multicolumn{3}{|c|}{ ROI 9} \\
\hline & $32 \pm 17$ & $6 \pm 4$ & $39 \pm 18$ & $26 \pm 14$ & $3 \pm 2$ & $29 \pm 15$ & $26 \pm 11$ & $3 \pm 3$ & $29 \pm 9$ \\
\hline
\end{tabular}

\subsubsection{Laser Doppler Flowmetry}

MCA occlusion resulted in a prompt reduction of CBF to $20 \pm 6 \%$ of baseline. The CBF stayed relatively constant over the 90 minutes of occlusion $(29 \pm 9 \%)$ and rising to $118 \pm 46 \%$ in the reperfusion phase. Flow transients as detected by LD developed in all the rats. The mean 
number of PIFTs was $4.6 \pm 1.8$ identical to that with laser speckle; $95.6 \%$ of them were temporally correlated (figure 9).

The amplitudes of the positive $(11.0 \pm 2.9 \%)$ and negative peaks $(8.7 \pm 1.3 \%)$ were comparable with the results by laser speckle. The wave morphology of all PIFTs recorded by LD was prominently hyperemic (71.7\%), with only $10.9 \%$ and $17.4 \%$ of the flow transients hypoperfusive or biphasic.

A
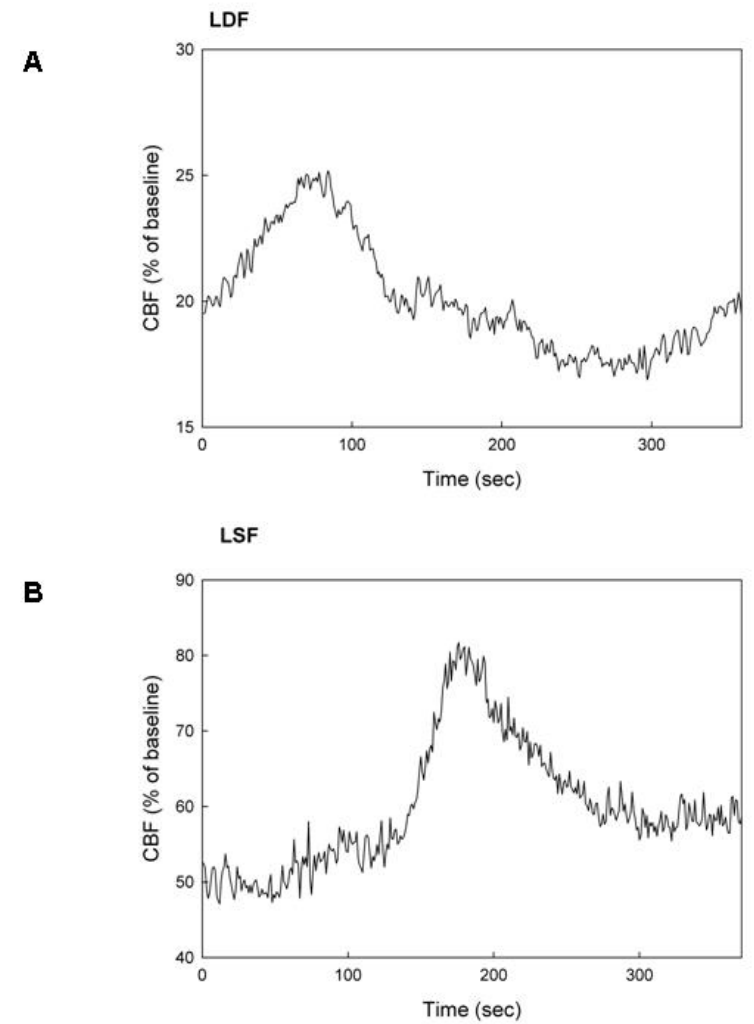

c

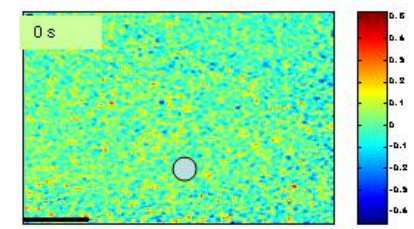

D

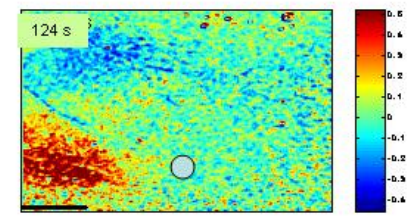

E

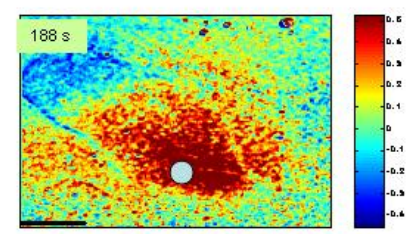

$\mathbf{F}$

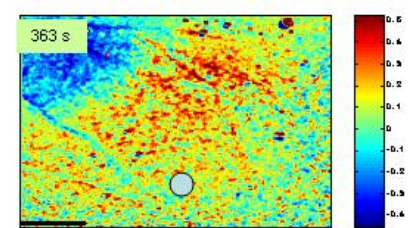

Figure 9. Anterio-posterior propagation of peri-infarct flow transients (C-F) detected by both laser Doppler (A) and laser speckle (B) can be seen over the right hemisphere 60 min post MCA occlusion. Relative timing of the color images (C-F) is indicated in the upper left corner of the panels.

\subsection{Hypothesis III/b.}

The mean flow values averaged over the 90 minutes of ischemia ranged between 34 and $64 \%$ by laser speckle over the nine ROIs. The mean residual flow in the peri-ischemic area (ROI 79: 54-64\%) was statistically higher $(\mathrm{p}<0.001)$ than the flow both over the penumbra (ROI 4- 
6: $34-45 \%$ and the core region (ROI 1-3: 35-39\%). By mapping the infarct zone with the ROI map we found that ROIs 7-9 represent the peri-ischemic area. The flow transients propagate mostly over the peri-ischemic (ROI 7-9) and the penumbral (ROI 4-6) region while we could detect only few flow transients over ROIs 1-3 which probably represent the core.

\subsubsection{Morphology of PIFTs}

We could distinguish 5 different morphologies of flow transients by LS as we found with the filament occlusion model (figure 7). The total number of events over ROI 4-9 was 201. Type II $(\mathrm{p}<0.001)$, III $(\mathrm{p}<0.01)$ and IV/V $(\mathrm{p}<0.05)$ shows regional heterogeneity while type I $(\mathrm{p}=0.06)$ does not. Type III, and IV/V occur over the penumbra while type II over the periischemic are more frequently.

\subsubsection{Amplitudes of PIFTS}

Both the peak to peak $(\mathrm{p}<0.001)$ and the positive $(\mathrm{p}<0.001)$ amplitudes of the PIFTs were higher over the peri-ischemic (ROI 7-9) versus penumbral (ROI 4-6) area (table 5).

\begin{tabular}{|c|c|c|c|c|c|c|c|c|}
\hline \multicolumn{3}{|l|}{ ROI 4} & \multicolumn{3}{|l|}{ ROI 5} & \multicolumn{3}{|l|}{ ROI 6} \\
\hline Type & Number & $\%$ & Type & Number & $\%$ & Type & Number & $\%$ \\
\hline$I$ & 15 & 42 & I & 7 & 27 & I & 12 & 46 \\
\hline II & 8 & 22 & II & 4 & 15 & II & 5 & 19 \\
\hline III & 10 & 28 & III & 7 & 27 & III & 7 & 27 \\
\hline IV & 2 & 6 & IV & 5 & 18 & IV & 2 & 8 \\
\hline v & 1 & 3 & v & 3 & 12 & v & 0 & 0 \\
\hline ROI 7 & & & ROI 8 & & & ROI 9 & & \\
\hline Type & Number & $\%$ & Type & Number & $\%$ & Type & Number & $\%$ \\
\hline$I$ & 16 & 48 & I & 22 & 56 & I & 23 & 62 \\
\hline II & 19 & 58 & II & 16 & 41 & II & 11 & 30 \\
\hline III & 2 & 6 & III & 1 & 3 & III & 3 & 8 \\
\hline IV & 0 & 0 & IV & 0 & 0 & IV & 0 & 0 \\
\hline v & 0 & 0 & v & 0 & 0 & v & 0 & 0 \\
\hline
\end{tabular}




\section{DISCUSSION}

The aim of this thesis is to investigate if PIFTs (total number, amplitude and morphology) are potent biomarkers in stroke research. Our results show that PIFTs are well coupled to DC changes and the number of PIFTs combined with the intra-ischemic CBF is a good, early predictor of outcome. Their morphology and the magnitude of the amplitude provide information about the infarct evolution and the hemodynamical status of the underlying brain tissue.

\subsection{The coupling rate between DC changes and PIFTs}

As discussed above (2.2.3), the criteria for the detection of PIFTs using one LD probe have been established in early studies (Luckl et al 2008; Luckl et al 2009). As a next step we wanted to know if PIFTs are well coupled to the SDs (gold standard) and therefore if they can reflect the expansion of the ischemic injury. We found in a large animal pool that the average coupling rate between spreading depolarization and PIFT was $93 \%$ with a better coupling rate when intra-ischemic flow is higher. The LD probe and the closest silver chloride electrode were $2 \mathrm{~mm}$ apart in the study, thus the coupling rate measured is an approximation. The experiment was designed to keep the dura intact (non-invasive), therefore the CBF and DC deflections had to be recorded over different locations. However, we presume that recording $\mathrm{CBF}$ and DC deflections over the same spot would probably result a similar coupling rate, because the propagation pattern of the PIFTs is very conservative (fronto-caudal) in this model of ischemia. The transients travel through the entire observational area over the convexity and the occurrence of the flow transients being close to $100 \%$ over each ROI (Luckl et al., 2009). Similarly, Kumagai et al reported a predictable propagation pattern in embolic (proximal) occlusion of MCA (Kumagai et al., 2011).

\subsection{The predictive value of PIFTs with regards to histological outcome}

Previous studies showed that spreading depolarizations play an important role in lesion progression during focal ischemia (Dijkhuizen et al 1999; Hossmann 1996; Nakamura et al 2010; Shin et al 2006). In our post-hoc analysis of 55 filament occluded animals, we found that the number of PIFTs in 90 min. ischemia is significantly $(p<0.01)$ higher in animals with substantial cortical infarct. The logistic regression analysis revealed that the number of PIFTs 
is the best single marker in the prediction of the bimodal outcome. Unfortunately, it does not give an accurate separation especially in the ISO group (table 2). However, a combination of the flow parameters increases the predictability. The combination of the CBF and the total number of PIFTs together seem to be a very accurate predictor (figure 4). Our results suggest that the penumbral tissue can be at risk even with higher intra-ischemic CBF due to good collateral supply when a large number of SDs propagates over the territory. On the contrary, tissue with severe ischemia can survive if only few depolarizations develop. The likelihood ratio test concluded that the combination of three different markers doesn't increase the predictability significantly. Although the role of the intraischemic CBF in the concept of viability thresholds (Symon et al., 1977, Mies et al., 1991, Hossmann, 1994, Burnett et al., 2005) and the reperfusion in the pathogenesis of ischemic stroke (Moore and Traystman, 1994, Aronowski et al., 1997) have also been extensively investigated, these flow parameters failed to prove their usefulness as good, single, early biomarkers in our study.

The Spearman analyses revealed further correlations between the flow parameters and the histological outcome. First of all, the number of PIFTs correlates well with the infarct size in each anesthetic subgroup. However, we observed in our early MCAO studies that the number of flow transients are good, but not perfect predictors of histological outcome. As figure 6 shows, for example, a large number of PIFTs is not necessarily associated with a large infarct area and vice versa. As we detailed in the previous paragraph, CBF is a very important co-factor in the prediction of histological outcome. The importance of perfusion deficit with regards to the outcome was also reported in another recent study (Dreier et al., 2013). The data also suggests that the number of PIFT is correlated with the extent of the edema. It is well known that spreading depolarization can cause cytotoxic (Klatzo, 1987, Dreier et al., 2009) as well as vasogenic edema by initiating a cascade that disrupts the blood brain barrier via an MMP-9 dependent mechanism (Gursoy-Ozdemir et al., 2004). On the other hand the disruption of BBB can facilitate the induction of SDs (Lapilover et al., 2012).

Another indirect proof that PIFTs can predict outcome is a study where we compared two anesthetics in the model of filament occlusion (Luckl et al., 2008). We found that $\alpha-$ chloralose was associated with a higher number of flow transients and a larger infarct size 
compared to volatile anesthetics (isoflurane). Our results are confirmed by other studies with electrophysiological recordings (Saito et al., 1997, Takeda et al., 2011).

It is important to accentuate that the location of a single LD probe plays an important role in counting PIFTs. In the filament occlusion model (proximal MCAO) we observed that the level of $\mathrm{CBF}$ in Sprague-Dawley rats is relatively homogenous in the MCA territory accessible after thinning of the calvarium medial to the crista temporalis with spreading depolarizations propagating over the whole penumbral and peri-ischemic area (Luckl et al., 2009). Therefore a single LD probe at any point of this area is sufficient to record the number of PIFTs. In the model of distal MCAO, however, the tissue directly medial to the crista appears to be part of the permanently depolarized ischemic core and consequently does not show PIFTs (Luckl et al., 2010). Thus, in the distal MCAO model the LD probe should be positioned closer to the midline if the experimenter aims to measure the number of PIFTs in the penumbra and peri-ischemic area.

\subsection{The predictive value of the morphological heterogeneity of the PIFTs}

We studied the morphological heterogeneity of the PIFTs in two different ischemia models. Distal occlusion of the MCA produces lesion in the fronto-parietal lobes while the proximal occlusion (filament) of the MCA affects a much larger area (basal ganglia, frontal, parietal and temporal lobe). We thinned the skull over a $6 \times 6 \mathrm{~mm}$ area in a distal MCAO study which gave us the opportunity to study the core and the penumbra as well as the peri-ischemic region even though we could not visualize the whole cycling propagation pattern of the PIFTs (Nakamura et al., 2010, Kumagai et al., 2011). A similar "window" size also enabled us to monitor the penumbral and peri-ischemic region in filament occlusion. The higher residual blood flow and amplitude of flow transients along with the larger percentage of type I (hyperemic) and type II (hyperemia dominant biphasic) flow transients in the medial ROIs in both models indicates that this region represents the peri-ischemic area (watershed zone between the MCA and ACA territories). The frequent reversals of blood flow in arterioles at the periphery of the MCA territory in the same ischemia model demonstrate that these arteriolar anastomoses (steal through collaterals) are functional (Pinard et al., 2002). In contrast, lower residual flow, and smaller amplitudes with higher percentage of hypoperfusive flow transients (type IV,V) is characteristic for the penumbra. Similarly, Kumagai et al 
reported in rat filament occlusion that monophasic reductions of $\mathrm{CBF}$ are dominant close to the core, whereas with increasing distance from the core, the flow transients are more biphasic or show monophasic increase (Kumagai et al 2011). The regional heterogeneity of flow transients was also reported in other rat (Nakamura et al 2010; Takeda et al 2011) and cat (Strong et al., 2007) studies.

The post-hoc Spearman analysis of flow data in filament occluded animals shows a strong positive correlation between the amplitude and the intra-ischemic flow. We found similar results in an early study (Luckl et al., 2009) but this is the first time when we managed to prove it in a larger animal pool. We conclude that the parameters, especially the amplitudes of the PIFTs and partly the morphology, are good indicators of the hemodynamic reserve (residual blood flow, collateral supply via the anastomotic network) of the underlying cortex.

It is likely that the different flow morphology reflect changes in regulation of the neurovascular unit during ischemia. There are presumptions in the literature that the flow morphology related to depolarizations is determined by active vasoconstrictor mechanisms. Evidence for perfusion loss attributed to vasoconstriction comes first from a group of papers from Dreier and colleagues, who simulated conditions likely to be present in patients following subarachnoidal hemorrhage (Dreier et al., 1998, Dreier et al., 2000). Several studies observed increased hypoperfusion in response to elevated potassium or SD in the presence of NO synthase inhibition (Dreier et al., 1995, Fabricius et al., 1995) consistent with the hypothesis that NO levels might determine the response to depolarization (Metea and Newman, 2006). In addition, vasodilators such as NO donors or the L-type calcium blocker nimodipine can reverse the spreading ischemia to almost normal spreading hyperemia with increased recovery of the slow potential change (Dreier et al., 1998, Windmuller et al., 2005). Our observation that hypoperfusion always precedes hyperemia is supported by these data and in concert with the results of Strong and colleagues (Strong et al 2007).

\subsection{Laser speckle versus laser Doppler measurements}

The CBF data recorded in our early studies by one or two LD probes at different sites in the ischemic cortex of rats indicated that the flow transients are mostly hyperemic events (7090\%) and did not show regional heterogeneity in morphology. The inconsistency between the predominately hyperemic flow transients observed with LD during MCA occlusion in the rat, 
and the suggestion of polymorphic and mostly hypoperfusive flow transients in mice from an early LS study (Shin et al 2006) compelled us to detect PIFTs with both techniques at the same time.

Albeit the LD and LS recordings were made over different part of the MCA territory (the closest points were about $3 \mathrm{~mm}$ apart) in our study the number of peri-infarct transients were the same, with $95.6 \%$ of them time correlated. The amplitudes of PIFT measured with LD were comparable with the values over the lateral and middle rows of ROIs (ROI 1-6) as monitored with LS. Since the flow transients were well "coupled" we concluded that LD is a suitable tool for counting PIFTs.

Dissimilarities in residual CBF and the occurrence of different PIFT morphologies were also unveiled by these two methods. The mean CBF during 90 min. ischemia in our series was $29 \pm 9 \%$ by LD compared with $36 \pm 10 \%$ to $42 \pm 10 \%$ (depending upon the ROI) by LS over the anterio-lateral area which is the closest territory to the LD recording site. Surprisingly the flow transients as measured by LD are more hyperemic than those measured by LS, with $71.7 \%$ of the flow transients characterized by a monophasic increase of flow, $17.4 \%$ being biphasic, and only $10.9 \%$ hypoperfusive. It is improbable that the difference in the ischemic flow ( $\mathrm{LD}=29 \%, \mathrm{LS}=36-42 \%$ ) can be interpreted by the ROIs of the $\mathrm{LS}$ being closer to the posterior circulation than the LD, as there was not an increasing rostral-caudal flow gradient seen by LS. In addition, in an early study in which two LD probes were positioned over the rostral and caudal part of the MCA territory the pattern of the PIFT morphologies was very similar over the two recording sites (unpublished observations).

It is possible however that these discrepancies can be due to potential differences in depth sensitivity of these two methods and a laminar (vertical) heterogeneity that may exist in the propagation of the flow transients. Dunn and colleagues (Dunn et al., 2001) observed a high correlation between LD and LS under conditions of SD and ischemia in rats, while other studies found some discrepancies (Durduran et al., 2004, Kharlamov et al., 2004, Royl et al., 2006). Laminar specificity during somatosensory stimulation imaged by functional magnetic resonance imaging (Silva and Koretsky, 2002), autoradiography (Gerrits et al., 2000) and during SD by LD flowmetry (Fabricius et al., 1997) has been shown in the rat. Using a laser with wavelength $780 \mathrm{~nm}$ and a $250 \mathrm{~mm}$ fiber separation Fabricius et al (Fabricius et al., 1997) 
observed that $47 \%$ of the signal comes from the most superficial $0.25 \mathrm{~mm}$, with $22 \%$ coming for the next $0.25 \mathrm{~mm}$ and $31 \%$ from tissue between $0.5 \mathrm{~mm}$ and $1.0 \mathrm{~mm}$ (containing layer IV) consistent with Monte-Carlo simulations of LD flowmetry, which indicate that the median sampling depth is approximately $550 \mu \mathrm{m}$ (Jakobsson and Nilsson, 1993). We speculate that laser speckle scans the shallower cortical layers $(>500 \mu \mathrm{m})$ but, unfortunately no one has ever made a quantitative depth sensitivity analysis for LS.

\subsection{The possible role of PIFT as biomarker in animal research}

Based on our findings, monitoring CBF changes appears to be very useful in the quality control of studies. A prompt drop in flow up to $20 \%$ of baseline in this model confirms a successful MCA occlusion, and a complete reperfusion indicates that the occlusion is really transient. In the clinic, a more realistic early time point for the start of any therapies is around 90 min after stroke onset. If our observation that intra-ischemic CBF together with PIFTs predict outcome after 90 min stroke onset is translated to a more clinically relevant animal study, our study provides a relatively simple tool to achieve treatment stratification. The use of the plot in figure 4 would allow the experimenter to enroll only those animals that would surely develop a cortical infarct in the natural course of the stroke when no neuroprotectant is given. Hence, the study population would become more homogeneous and fewer animals would be needed.

\subsection{The possible role of PIFT as biomarker in clinical studies}

Over many years, it was believed that spreading depolarization plays no significant role in human brain disorders. One of the reasons for the skepticism in SDs was the difficulty in detecting the focal depolarization waves non-invasively (Back et al., 2000). The first successful detection of SDs was reported in patients with traumatic brain injury based on invasive recording of the subdural electrocorticogram (Strong et al., 2002). Patients who undergo neurosurgery including craniotomy because of their acute brain condition, or the introduction of decompressive surgery as treatment option for malignant hemispheric stroke provide the opportunity to use cortical electrode strips. The recent series of invasive recordings of SDs by the Co-Operative Study on Brain Injury Depolarizations (COSBID; see www.cosbid.org) provided evidence that SD occurs in a large percentage of patients with 
traumatic brain injury (Hartings et al., 2008) subarachnoid hemorrhage (Dreier et al 2009) and malignant hemispheric stroke (Dohmen et al., 2008). The emerging evidence for occurrence of SDs in patients with acute brain injury is giving us better understandings of the pathophysiology of these neurological conditions. The main benefit is that we will have a chance to apply an adequate treatment for patient with tissue- at- risk. First of all, we should determine the extent from which SD are apparently harmful and test the hypothesis that SDs predict bad outcome independent of classical risk factors (Lauritzen et al., 2011). Another direction of research might be the clinical tests of agents which can inhibit the propagation or the deleterious effects of SDs. For example, a recent study suggests that ketamine or another NMDA receptor agonist may represent an effective treatment (Hertle et al., 2012). It is important to note that the invasive methodology used in the clinical studies limits the indication for SD studies. Non-invasive recordings of SDs would allow us to investigate patients whose medical condition does not require craniotomy: acute ACM thrombosis with non-malignant course, mild/moderate traumatic brain injury etc. As we discussed in the Introduction, monitoring flow transients could be a potent biomarker in acute ischemic stroke. Invasive subdural LD monitoring is already used in human studies (Dreier et al 2009). In the future non-invasive, transcranial optical imaging techniques such as diffuse correlation spectroscopy (Durduran et al 2010) and ultrasound tagged near infrared spectroscopy (Schytz et al., 2012) could be used for this purpose. 


\section{REFERENCE LIST}

Aitken PG, Tombaugh GC, Turner DA, Somjen GG (1998) Similar propagation of SD and hypoxic SD-like depolarization in rat hippocampus recorded optically and electrically. J Neurophysiol 80:1514-1521.

Aronowski J, Strong R, Grotta JC (1997) Reperfusion injury: demonstration of brain damage produced by reperfusion after transient focal ischemia in rats. J Cereb Blood Flow Metab 17:1048-1056.

Ayata C, Moskowitz MA (2006) Cortical spreading depression confounds concentrationdependent pial arteriolar dilation during N-methyl-D-aspartate superfusion. Am J Physiol Heart Circ Physiol 290:H1837-1841.

Ayata C, Shin HK, Salomone S, Ozdemir-Gursoy Y, Boas DA, Dunn AK, Moskowitz MA (2004) Pronounced hypoperfusion during spreading depression in mouse cortex. J Cereb Blood Flow Metab 24:1172-1182.

Back T, Hirsch JG, Szabo K, Gass A (2000) Failure to demonstrate peri-infarct depolarizations by repetitive MR diffusion imaging in acute human stroke. Stroke 31:2901-2906.

Bandyopadhyay R, Gittings AS, Suh SS, Dixon PK, Durian DJ (2005) Speckle-visibility spectroscopy: A tool to study time-varying dynamics. Rev Sci Instrument 76:093110.

Bari F, Louis TM, Busija DW (1998a) Effects of ischemia on cerebral arteriolar dilation to arterial hypoxia in piglets. Stroke 29:222-227; discussion 227-228.

Bari F, Paprika D (2000) Changes in cerebrovascular reactivity after stimulation and depletion of sensory fibers in rats. In: Ischemic Blood Flow in the Brain(Fukuuchi, Y. T., M.; Koto, A., ed), pp 289-295 Tokyo: Springer Publishers.

Bari F, Paprika D, Jancso G, Domoki F (2000) Capsaicin-sensitive mechanisms are involved in cortical spreading depression-associated cerebral blood flow changes in rats. Neurosci Lett 292:17-20.

Bari F, Thore CR, Louis TM, Busija DW (1998b) Inhibitory effects of hypoxia and adenosine on N-methyl-D-aspartate-induced pial arteriolar dilation in piglets. Brain Res 780:237244.

Basarsky TA, Duffy SN, Andrew RD, MacVicar BA (1998) Imaging spreading depression and associated intracellular calcium waves in brain slices. J Neurosci 18:7189-7199.

Brennan KC, Beltran-Parrazal L, Lopez-Valdes HE, Theriot J, Toga AW, Charles AC (2007) Distinct vascular conduction with cortical spreading depression. J Neurophysiol 97:4143-4151.

Briers JD (2001) Laser Doppler, speckle and related techniques for blood perfusion mapping and imaging. Physiol Meas 22:R35-66.

Burnett MG, Detre JA, Greenberg JH (2005) Activation-flow coupling during graded cerebral ischemia. Brain Res 1047:112-118. 
Busija DW (1996) Nervous control of the cerebral circulation. In: Nervous Control of the Circulation(Benett, T. G., S.M., ed), pp 177-206 Amsterdam: Harwood Academic Publisher,.

Busija DW, Bari F, Domoki F, Horiguchi T, Shimizu K (2008) Mechanisms involved in the cerebrovascular dilator effects of cortical spreading depression. Prog Neurobiol 86:379-395.

Busija DW, Bari F, Domoki F, Louis T (2007) Mechanisms involved in the cerebrovascular dilator effects of N-methyl-d-aspartate in cerebral cortex. Brain Res Rev 56:89-100.

Collewijn H, Harreveld AV (1966) Membrane potential of cerebral cortical cells during reading depression and asyxia. Exp Neurol 15:425-436.

Colonna DM, Meng W, Deal DD, Busija DW (1994) Calcitonin gene-related peptide promotes cerebrovascular dilation during cortical spreading depression in rabbits. Am J Physiol 266:H1095-1102.

Colonna DM, Meng W, Deal DD, Gowda M, Busija DW (1997) Neuronal NO promotes cerebral cortical hyperemia during cortical spreading depression in rabbits. Am $\mathbf{J}$ Physiol 272:H1315-1322.

Czeh G, Aitken PG, Somjen GG (1993) Membrane currents in CA1 pyramidal cells during spreading depression (SD) and SD-like hypoxic depolarization. Brain Res 632:195208.

Czeh G, Somjen GG (1990) Hypoxic failure of synaptic transmission in the isolated spinal cord, and the effects of divalent cations. Brain Res 527:224-233.

Davydov VI, Koroleva VI (1993) [The modelling of the modes of propagation of SD waves in brain structures taking into account the nonuniform density of the active elements]. $\mathrm{Zh}$ Vyssh Nerv Deiat Im I P Pavlova 43:695-706.

de Neverlee H, Laget P (1965) [Propagation of spreading depression and regional cortical maturation in the young rabbit]. J Physiol (Paris) 57:667.

Dietz RM, Weiss JH, Shuttleworth CW (2008) Zn2+ influx is critical for some forms of spreading depression in brain slices. J Neurosci 28:8014-8024.

Dijkhuizen RM, Beekwilder JP, van der Worp HB, Berkelbach van der Sprenkel JW, Tulleken KA, Nicolay K (1999) Correlation between tissue depolarizations and damage in focal ischemic rat brain. Brain Res 840:194-205.

Dohmen C, Sakowitz OW, Fabricius M, Bosche B, Reithmeier T, Ernestus RI, Brinker G, Dreier JP, Woitzik J, Strong AJ, Graf R (2008) Spreading depolarizations occur in human ischemic stroke with high incidence. Ann Neurol 63:720-728.

Domoki F, Perciaccante JV, Veltkamp R, Bari F, Busija DW (1999) Mitochondrial potassium channel opener diazoxide preserves neuronal-vascular function after cerebral ischemia in newborn pigs. Stroke 30:2713-2718; discussion 2718-2719.

Dreier JP (2011) The role of spreading depression, spreading depolarization and spreading ischemia in neurological disease. Nat Med 17:439-447.

Dreier JP, Ebert N, Priller J, Megow D, Lindauer U, Klee R, Reuter U, Imai Y, Einhaupl KM, Victorov I, Dirnagl U (2000) Products of hemolysis in the subarachnoid space 
inducing spreading ischemia in the cortex and focal necrosis in rats: a model for delayed ischemic neurological deficits after subarachnoid hemorrhage? J Neurosurg 93:658-666.

Dreier JP, Korner K, Ebert N, Gorner A, Rubin I, Back T, Lindauer U, Wolf T, Villringer A, Einhaupl KM, Lauritzen M, Dirnagl U (1998) Nitric oxide scavenging by hemoglobin or nitric oxide synthase inhibition by N-nitro-L-arginine induces cortical spreading ischemia when $\mathrm{K}+$ is increased in the subarachnoid space. J Cereb Blood Flow Metab 18:978-990.

Dreier JP, Korner K, Gorner A, Lindauer U, Weih M, Villringer A, Dirnagl U (1995) Nitric oxide modulates the CBF response to increased extracellular potassium. J Cereb Blood Flow Metab 15:914-919.

Dreier JP, Major S, Manning A, Woitzik J, Drenckhahn C, Steinbrink J, Tolias C, OliveiraFerreira AI, Fabricius M, Hartings JA, Vajkoczy P, Lauritzen M, Dirnagl U, Bohner G, Strong AJ (2009) Cortical spreading ischaemia is a novel process involved in ischaemic damage in patients with aneurysmal subarachnoid haemorrhage. Brain 132:1866-1881.

Dreier JP, Petzold G, Tille K, Lindauer U, Arnold G, Heinemann U, Einhaupl KM, Dirnagl U (2001) Ischaemia triggered by spreading neuronal activation is inhibited by vasodilators in rats. J Physiol 531:515-526.

Dreier JP, Victorov IV, Petzold GC, Major S, Windmuller O, Fernandez-Klett F, Kandasamy M, Dirnagl U, Priller J (2013) Electrochemical Failure of the Brain Cortex Is More Deleterious When it Is Accompanied by Low Perfusion. Stroke 44:490-496.

Drenckhahn C, Winkler MK, Major S, Scheel M, Kang EJ, Pinczolits A, Grozea C, Hartings JA, Woitzik J, Dreier JP (2012) Correlates of spreading depolarization in human scalp electroencephalography. Brain 135:853-868.

Dunn AK, Bolay H, Moskowitz MA, Boas DA (2001) Dynamic imaging of cerebral blood flow using laser speckle. J Cereb Blood Flow Metab 21:195-201.

Durduran T, Burnett MG, Yu G, Zhou C, Furuya D, Yodh AG, Detre JA, Greenberg JH (2004) Spatiotemporal quantification of cerebral blood flow during functional activation in rat somatosensory cortex using laser-speckle flowmetry. J Cereb Blood Flow Metab 24:518-525.

Durduran T, Zhou C, Buckley EM, Kim MN, Yu G, Choe R, Gaynor JW, Spray TL, Durning SM, Mason SE, Montenegro LM, Nicolson SC, Zimmerman RA, Putt ME, Wang J, Greenberg JH, Detre JA, Yodh AG, Licht DJ (2010) Optical measurement of cerebral hemodynamics and oxygen metabolism in neonates with congenital heart defects. $\mathrm{J}$ Biomed Opt 15:037004.

Fabricius M, Akgoren N, Dirnagl U, Lauritzen M (1997) Laminar analysis of cerebral blood flow in cortex of rats by laser-Doppler flowmetry: a pilot study. J Cereb Blood Flow Metab 17:1326-1336. 
Fabricius M, Akgoren N, Lauritzen M (1995) Arginine-nitric oxide pathway and cerebrovascular regulation in cortical spreading depression. Am J Physiol 269:H2329.

Farkas E, Bari F, Obrenovitch TP (2010) Multi-modal imaging of anoxic depolarization and hemodynamic changes induced by cardiac arrest in the rat cerebral cortex. Neuroimage 51:734-742.

Gerriets T, Stolz E, Walberer M, Muller C, Kluge A, Bachmann A, Fisher M, Kaps M, Bachmann G (2004) Noninvasive quantification of brain edema and the spaceoccupying effect in rat stroke models using magnetic resonance imaging. Stroke 35:566-571.

Gerrits RJ, Raczynski C, Greene AS, Stein EA (2000) Regional cerebral blood flow responses to variable frequency whisker stimulation: an autoradiographic analysis. Brain Res 864:205-212.

Girouard H, Iadecola C (2006) Neurovascular coupling in the normal brain and in hypertension, stroke, and Alzheimer disease. J Appl Physiol 100:328-335.

Goadsby PJ, Hoskin KL (1994) Cerebral blood flow is not coupled to neuronal activity during stimulation of the facial nerve vasodilator system. Brain Res 647:192-198.

Goadsby PJ, Kaube H, Hoskin KL (1992) Nitric oxide synthesis couples cerebral blood flow and metabolism. Brain Res 595:167-170.

Goodman J (1985) Statistical optics. Hoboken, NJ: John Wiley \& Sons.

Grinvald A, Segal M, Kuhnt U, Hildesheim R, Manker A, Anglister L, Freeman JA (1986) Real-time optical mapping of neuronal activity in vertebrate CNS in vitro and in vivo. Soc Gen Physiol Ser 40:165-197.

Gursoy-Ozdemir Y, Qiu J, Matsuoka N, Bolay H, Bermpohl D, Jin H, Wang X, Rosenberg GA, Lo EH, Moskowitz MA (2004) Cortical spreading depression activates and upregulates MMP-9. J Clin Invest 113:1447-1455.

Hansen AJ, Quistorff B, Gjedde A (1980) Relationship between local changes in cortical blood flow and extracellular K+ during spreading depression. Acta Physiol Scand 109:1-6.

Hartings JA, Bullock MR, Okonkwo DO, Murray LS, Murray GD, Fabricius M, Maas AI, Woitzik J, Sakowitz O, Mathern B, Roozenbeek B, Lingsma H, Dreier JP, Puccio AM, Shutter LA, Pahl C, Strong AJ (2011) Spreading depolarisations and outcome after traumatic brain injury: a prospective observational study. Lancet Neurol 10:10581064.

Hartings JA, Gugliotta M, Gilman C, Strong AJ, Tortella FC, Bullock MR (2008) Repetitive cortical spreading depolarizations in a case of severe brain trauma. Neurol Res 30:876882.

Herreras O, Largo C, Ibarz JM, Somjen GG, Martin del Rio R (1994) Role of neuronal synchronizing mechanisms in the propagation of spreading depression in the in vivo hippocampus. J Neurosci 14:7087-7098. 
Herreras O, Somjen GG (1993) Effects of prolonged elevation of potassium on hippocampus of anesthetized rats. Brain Res 617:194-204.

Hertle DN, Dreier JP, Woitzik J, Hartings JA, Bullock R, Okonkwo DO, Shutter LA, Vidgeon S, Strong AJ, Kowoll C, Dohmen C, Diedler J, Veltkamp R, Bruckner T, Unterberg AW, Sakowitz OW (2012) Effect of analgesics and sedatives on the occurrence of spreading depolarizations accompanying acute brain injury. Brain 135:2390-2398.

Hossmann KA (1994) Viability thresholds and the penumbra of focal ischemia. Ann Neurol 36:557-565.

Hossmann KA (1996) Periinfarct depolarizations. Cerebrovasc Brain Metab Rev 8:195-208.

Iadecola C, Nedergaard M (2007) Glial regulation of the cerebral microvasculature. Nat Neurosci 10:1369-1376.

Iijima T, Mies G, Hossmann KA (1992) Repeated negative DC deflections in rat cortex following middle cerebral artery occlusion are abolished by MK-801: effect on volume of ischemic injury. J Cereb Blood Flow Metab 12:727-733.

Jakobsson A, Nilsson GE (1993) Prediction of sampling depth and photon pathlength in laser Doppler flowmetry. Med Biol Eng Comput 31:301-307.

Kager H, Wadman WJ, Somjen GG (2000) Simulated seizures and spreading depression in a neuron model incorporating interstitial space and ion concentrations. J Neurophysiol 84:495-512.

Kager H, Wadman WJ, Somjen GG (2002) Conditions for the triggering of spreading depression studied with computer simulations. J Neurophysiol 88:2700-2712.

Kharlamov A, Brown BR, Easley KA, Jones SC (2004) Heterogeneous response of cerebral blood flow to hypotension demonstrated by laser speckle imaging flowmetry in rats. Neurosci Lett 368:151-156.

Klatzo I (1987) Pathophysiological aspects of brain edema. Acta Neuropathol 72:236-239.

Kohl M, Lindauer U, Royl G, Kuhl M, Gold L, Villringer A, Dirnagl U (2000) Physical model for the spectroscopic analysis of cortical intrinsic optical signals. Phys Med Biol 45:3749-3764.

Kow LM, van Harreveld A (1972) Ion and water movements in isolated chicken retinas during spreading depression. Neurobiology 2:61-69.

Kumagai T, Walberer M, Nakamura H, Endepols H, Sue M, Vollmar S, Adib S, Mies G, Yoshimine T, Schroeter M, Graf R (2011) Distinct spatiotemporal patterns of spreading depolarizations during early infarct evolution: evidence from real-time imaging. J Cereb Blood Flow Metab 31:580-592.

La Manna JCR, M. (1975) Effect of ouabain and phenobarbital on oxidative metabolic activity associated with spreading cortical depression in cats. Brain Res 88:145-149.

Lapilover EG, Lippmann K, Salar S, Maslarova A, Dreier JP, Heinemann U, Friedman A (2012) Peri-infarct blood-brain barrier dysfunction facilitates induction of spreading depolarization associated with epileptiform discharges. Neurobiol Dis 48:495-506. 
Largo C, Cuevas P, Somjen GG, Martin del Rio R, Herreras O (1996) The effect of depressing glial function in rat brain in situ on ion homeostasis, synaptic transmission, and neuron survival. J Neurosci 16:1219-1229.

Largo C, Ibarz JM, Herreras O (1997) Effects of the gliotoxin fluorocitrate on spreading depression and glial membrane potential in rat brain in situ. J Neurophysiol 78:295307.

Lauritzen M (1994) Pathophysiology of the migraine aura. The spreading depression theory. Brain 117 ( Pt 1):199-210.

Lauritzen M, Dreier JP, Fabricius M, Hartings JA, Graf R, Strong AJ (2011) Clinical relevance of cortical spreading depression in neurological disorders: migraine, malignant stroke, subarachnoid and intracranial hemorrhage, and traumatic brain injury. J Cereb Blood Flow Metab 31:17-35.

Leao AA (1944) Spreading depression of activity in the cerebral cortex. J Neurophysiol 7:359-390.

Leao AA (1947) Further observations on the spreading depression of activity in the cerebral cortex. J Neurophysiol 10:409-414.

Luckl J, Baker W, Sun ZH, Durduran T, Yodh AG, Greenberg JH (2010) The biological effect of contralateral forepaw stimulation in rat focal cerebral ischemia: a multispectral optical imaging study. Front Neuroenergetics 2.

Luckl J, Zhou C, Durduran T, Yodh AG, Greenberg JH (2009) Characterization of periinfarct flow transients with laser speckle and Doppler after middle cerebral artery occlusion in the rat. J Neurosci Res 87:1219-1229.

Martins-Ferreira H, De Oliveira Castro G, Struchiner CJ, Rodrigues PS (1974) Circling spreading depression in isolated chick retina. J Neurophysiol 37:773-784.

Matsushima K, Hogan MJ, Hakim AM (1996) Cortical spreading depression protects against subsequent focal cerebral ischemia in rats. J Cereb Blood Flow Metab 16:221-226.

Meng W, Busija DW (1996) Oxygen radicals do not play a role in arteriolar dilation during cortical spreading depression. J Cereb Blood Flow Metab 16:175-179.

Metea MR, Newman EA (2006) Glial cells dilate and constrict blood vessels: a mechanism of neurovascular coupling. J Neurosci 26:2862-2870.

Mies G, Iijima T, Hossmann KA (1993) Correlation between peri-infarct DC shifts and ischaemic neuronal damage in rat. Neuroreport 4:709-711.

Mies G, Ishimaru S, Xie Y, Seo K, Hossmann KA (1991) Ischemic thresholds of cerebral protein synthesis and energy state following middle cerebral artery occlusion in rat. $\mathrm{J}$ Cereb Blood Flow Metab 11:753-761.

Moore LE, Traystman RJ (1994) Role of oxygen free radicals and lipid peroxidation in cerebral reperfusion injury. Adv Pharmacol 31:565-576.

Mori S, Miller WH, Tomita T (1976) Microelectrode study of spreading depression (SD) in frog retina--general observations of field potential associated with SD. Jpn J Physiol 26:203-217. 
Muller M, Somjen GG (2000a) $\mathrm{Na}(+)$ and $\mathrm{K}(+)$ concentrations, extra- and intracellular voltages, and the effect of TTX in hypoxic rat hippocampal slices. J Neurophysiol 83:735-745.

Muller M, Somjen GG (2000b) $\mathrm{Na}(+)$ dependence and the role of glutamate receptors and $\mathrm{Na}(+)$ channels in ion fluxes during hypoxia of rat hippocampal slices. J Neurophysiol 84:1869-1880.

Mutch WA, Hansen AJ (1984) Extracellular pH changes during spreading depression and cerebral ischemia: mechanisms of brain $\mathrm{pH}$ regulation. J Cereb Blood Flow Metab 4:17-27.

Nakamura H, Strong AJ, Dohmen C, Sakowitz OW, Vollmar S, Sue M, Kracht L, Hashemi P, Bhatia R, Yoshimine T, Dreier JP, Dunn AK, Graf R (2010) Spreading depolarizations cycle around and enlarge focal ischaemic brain lesions. Brain 133:1994-2006.

Nedergaard M, Hansen AJ (1988) Spreading depression is not associated with neuronal injury in the normal brain. Brain Res 449:395-398.

Nicholson C (1984) Comparative neurophysiology of spreading depression in the cerebellum. An Acad Bras Cienc 56:481-494.

Nozari A, Dilekoz E, Sukhotinsky I, Stein T, Eikermann-Haerter K, Liu C, Wang Y, Frosch MP, Waeber C, Ayata C, Moskowitz MA (2010) Microemboli may link spreading depression, migraine aura, and patent foramen ovale. Ann Neurol 67:221-229.

Obrenovitch TP, Zilkha E (1995) High extracellular potassium, and not extracellular glutamate, is required for the propagation of spreading depression. J Neurophysiol 73:2107-2114.

Obrig H, Villringer A (2003) Beyond the visible--imaging the human brain with light. J Cereb Blood Flow Metab 23:1-18.

Oliveira-Ferreira AI, Milakara D, Alam M, Jorks D, Major S, Hartings JA, Luckl J, Martus P, Graf R, Dohmen C, Bohner G, Woitzik J, Dreier JP (2010) Experimental and preliminary clinical evidence of an ischemic zone with prolonged negative DC shifts surrounded by a normally perfused tissue belt with persistent electrocorticographic depression. J Cereb Blood Flow Metab 30:1504-1519.

Parthasarathy AB, Tom WJ, Gopal A, Zhang X, Dunn AK (2008) Robust flow measurement with multi-exposure speckle imaging. Opt Express 16:1975-1989.

Petzold GC, Windmuller O, Haack S, Major S, Buchheim K, Megow D, Gabriel S, Lehmann TN, Drenckhahn C, Peters O, Meierkord H, Heinemann U, Dirnagl U, Dreier JP (2005) Increased extracellular $\mathrm{K}+$ concentration reduces the efficacy of N-methyl-Daspartate receptor antagonists to block spreading depression-like depolarizations and spreading ischemia. Stroke 36:1270-1277.

Piilgaard H, Lauritzen M (2009) Persistent increase in oxygen consumption and impaired neurovascular coupling after spreading depression in rat neocortex. J Cereb Blood Flow Metab 29:1517-1527.

Pinard E, Nallet H, MacKenzie ET, Seylaz J, Roussel S (2002) Penumbral microcirculatory changes associated with peri-infarct depolarizations in the rat. Stroke 33:606-612. 
Ramos JG (1975) Ionic movements in the isolated chicken retina during spreading depression. Acta Physiol Lat Am 25:112-119.

Reuter U, Weber JR, Gold L, Arnold G, Wolf T, Dreier J, Lindauer U, Dirnagl U (1998) Perivascular nerves contribute to cortical spreading depression-associated hyperemia in rats. Am J Physiol 274:H1979-1987.

Roy CS, Sherrington CS (1890) On the Regulation of the Blood-supply of the Brain. J Physiol 11:85-158 117.

Royl G, Leithner C, Sellien H, Muller JP, Megow D, Offenhauser N, Steinbrink J, KohlBareis M, Dirnagl U, Lindauer U (2006) Functional imaging with laser speckle contrast analysis: vascular compartment analysis and correlation with laser Doppler flowmetry and somatosensory evoked potentials. Brain Res 1121:95-103.

Saito R, Graf R, Hubel K, Fujita T, Rosner G, Heiss WD (1997) Reduction of infarct volume by halothane: effect on cerebral blood flow or perifocal spreading depression-like depolarizations. J Cereb Blood Flow Metab 17:857-864.

Schytz HW, Guo S, Jensen LT, Kamar M, Nini A, Gress DR, Ashina M (2012) A new technology for detecting cerebral blood flow: a comparative study of ultrasound tagged NIRS and 133Xe-SPECT. Neurocrit Care 17:139-145.

Seitz I, Dirnagl U, Lindauer U (2004) Impaired vascular reactivity of isolated rat middle cerebral artery after cortical spreading depression in vivo. J Cereb Blood Flow Metab 24:526-530.

Shibata M, Leffler CW, Busija DW (1992) Pial arteriolar constriction following cortical spreading depression is mediated by prostanoids. Brain Res 572:190-197.

Shin HK, Dunn AK, Jones PB, Boas DA, Moskowitz MA, Ayata C (2006) Vasoconstrictive neurovascular coupling during focal ischemic depolarizations. J Cereb Blood Flow Metab 26:1018-1030.

Siesjo BK (1993) A new perspective on ischemic brain damage? Prog Brain Res 96:1-9.

Silva AC, Koretsky AP (2002) Laminar specificity of functional MRI onset times during somatosensory stimulation in rat. Proc Natl Acad Sci U S A 99:15182-15187.

Somjen GG (2004) Ions in the brain. Oxford, UK: Oxford University Press.

Somjen GG, Aitken PG (1984) The ionic and metabolic responses associated with neuronal depression of Leao's type in cerebral cortex and in hippocampal formation. An Acad Bras Cienc 56:495-504.

Sonn J, Mayevsky A (2012) Responses to Cortical Spreading Depression under Oxygen Deficiency. Open Neurol J 6:6-17.

Strong AJ, Anderson PJ, Watts HR, Virley DJ, Lloyd A, Irving EA, Nagafuji T, Ninomiya M, Nakamura H, Dunn AK, Graf R (2007) Peri-infarct depolarizations lead to loss of perfusion in ischaemic gyrencephalic cerebral cortex. Brain 130:995-1008.

Strong AJ, Bezzina EL, Anderson PJ, Boutelle MG, Hopwood SE, Dunn AK (2006) Evaluation of laser speckle flowmetry for imaging cortical perfusion in experimental stroke studies: quantitation of perfusion and detection of peri-infarct depolarisations. $\mathbf{J}$ Cereb Blood Flow Metab 26:645-653. 
Strong AJ, Dardis R (2005) Depolarisation phenomena in traumatic and ischaemic brain injury. Adv Tech Stand Neurosurg 30:3-49.

Strong AJ, Fabricius M, Boutelle MG, Hibbins SJ, Hopwood SE, Jones R, Parkin MC, Lauritzen M (2002) Spreading and synchronous depressions of cortical activity in acutely injured human brain. Stroke 33:2738-2743.

Sukhotinsky I, Dilekoz E, Moskowitz MA, Ayata C (2008) Hypoxia and hypotension transform the blood flow response to cortical spreading depression from hyperemia into hypoperfusion in the rat. J Cereb Blood Flow Metab 28:1369-1376.

Symon L, Branston NM, Strong AJ, Hope TD (1977) The concepts of thresholds of ischaemia in relation to brain structure and function. J Clin Pathol Suppl (R Coll Pathol) 11:149154.

Takano T, Tian GF, Peng W, Lou N, Lovatt D, Hansen AJ, Kasischke KA, Nedergaard M (2007) Cortical spreading depression causes and coincides with tissue hypoxia. Nat Neurosci 10:754-762.

Takeda Y, Zhao L, Jacewicz M, Pulsinelli WA, Nowak TS, Jr. (2011) Metabolic and perfusion responses to recurrent peri-infarct depolarization during focal ischemia in the Spontaneously Hypertensive Rat: dominant contribution of sporadic CBF decrements to infarct expansion. J Cereb Blood Flow Metab 31:1863-1873.

Theis M, Jauch R, Zhuo L, Speidel D, Wallraff A, Doring B, Frisch C, Sohl G, Teubner B, Euwens C, Huston J, Steinhauser C, Messing A, Heinemann U, Willecke K (2003) Accelerated hippocampal spreading depression and enhanced locomotory activity in mice with astrocyte-directed inactivation of connexin43. J Neurosci 23:766-776.

Tower DB, Young OM (1973) The activities of butyrylcholinesterase and carbonic anhydrase, the rate of anaerobic glycolysis, and the question of a constant density of glial cells in cerebral cortices of various mammalian species from mouse to whale. J Neurochem 20:269-278.

Tuckwell HC (1981) Simplified reaction-diffusion equations for potassium and calcium ion concentrations during spreading cortical depression. Int J Neurosci 12:95-107.

Van Harreveld A, Fifkova E (1970) Glutamate release from the retina during spreading depression. J Neurobiol 2:13-29.

Vilagi I, Klapka N, Luhmann HJ (2001) Optical recording of spreading depression in rat neocortical slices. Brain Res 898:288-296.

Wadman WJ, Juta AJ, Kamphuis W, Somjen GG (1992) Current source density of sustained potential shifts associated with electrographic seizures and with spreading depression in rat hippocampus. Brain Res 570:85-91.

Walz W (1997) Role of astrocytes in the spreading depression signal between ischemic core and penumbra. Neurosci Biobehav Rev 21:135-142.

Wang Z, Hughes S, Dayasundara S, Menon RS (2007) Theoretical and experimental optimization of laser speckle contrast imaging for high specificity to brain microcirculation. J Cereb Blood Flow Metab 27:258-269. 
Windmuller O, Lindauer U, Foddis M, Einhaupl KM, Dirnagl U, Heinemann U, Dreier JP (2005) Ion changes in spreading ischaemia induce rat middle cerebral artery constriction in the absence of NO. Brain 128:2042-2051.

Yanamoto H, Hong SC, Soleau S, Kassell NF, Lee KS (1996) Mild postischemic hypothermia limits cerebral injury following transient focal ischemia in rat neocortex. Brain Res 718:207-211.

Yanamoto H, Miyamoto S, Tohnai N, Nagata I, Xue JH, Nakano Y, Nakajo Y, Kikuchi H (2005) Induced spreading depression activates persistent neurogenesis in the subventricular zone, generating cells with markers for divided and early committed neurons in the caudate putamen and cortex. Stroke 36:1544-1550.

Zhou C, Shimazu T, Durduran T, Luckl J, Kimberg DY, Yu G, Chen XH, Detre JA, Yodh AG, Greenberg JH (2008) Acute functional recovery of cerebral blood flow after forebrain ischemia in rat. J Cereb Blood Flow Metab 28:1275-1284. 


\section{ACKNOWLEDGEMENTS}

I would like to thank my supervisor, Prof. Ferenc Bari, for his mentorship. Without his valuable advice, guidance and helpful attitude, it would not have been possible for me to present my research findings in this dissertation. This work was supported by the grant TÁMOP-4.2.2.A-11/1/KONV-2012-0052.

I would like to express my sincere gratitude to Prof. Joel H. Greenberg (University of Pennsylvania, Philadelphia, USA), who gave me the opportunity to master the animal models of ischemic stroke in his laboratory. His professional support, advice and infinite patience contributed significantly to the successful execution of the experiments and the publication of the results.

Special thanks go to Professor Jens P. Dreier (Charité Universitätsmedizin, Berlin, Germany), my current boss, who invited me to join his research group, thus enabling me to deepen my scientific knowledge through animal experiments and clinical experience in the scientific field of spreading depolarization. His valuable advice contributed greatly to this thesis.

I am thankful to Prof. Ferenc Gallyas (University of Pécs, Hungary), Prof. András Büki (University of Pécs, Hungary), and John T. Povlishock (Virginia Commonwealth University, Richmond, USA) who introduced me to the basics of scientific work in their laboratories and supported me in the initial steps.

I would like to express my appreciation to my colleagues and fellow authors. Chao Zhou PhD, Wesley Baker PhD, Turgut Durduran PhD, Erzsébet Kövesdi PhD, Sebastian Major MD, Ana I. Oliveira-Ferreira PhD and Dirk Wiesenthal contributed markedly to the successful implementation of the experiments with their professional competence and friendly support.

Last but not least, I am grateful to my Family for the unconditional love, patience and continuous support given to me throughout the course of my work. 


\section{PUBLICATION LIST}

Total IF: 26.0 Total Citations: 171 (google scholar)

\section{PUBLICATIONS RELATED TO THE SUBJECT OF THE THESIS}

1. Luckl J, Zhou C, Durduran T, Yodh AG, Greenberg JH. Characterization of peri-infarct flow transients with laser speckle and laser Doppler during middle cerebral artery occlusion in rat. J Neurosci Res. 2009 Apr; 87(5):1219-29

IF: 2.986 Cit: 19

2. Luckl J, Baker W, Sun ZH, Durduran T, Yodh AG, Greenberg JH. The biological effect of contralateral forepaw stimulation in rat focal cerebral ischemia: a multispectral optical imaging study. Front Neuroenergetics. 2010 Jul 30; 2.

IF: still computing Cit: 10

3. Lückl J, Dreier JP, Szabados T, Wiesenthal D, Bari F, Greenberg JH. Peri-infarct flow transients predict outcome in rat focal brain ischemia. Neuroscience. 2012 Dec; 226:197-207.

IF: 3.122 Cit: 0

\section{PUBLICATIONS NOT RELATED TO THE SUBJECT OF THE THESIS}

1. Lückl J, Farkas O, Pál J, Kövesdi E, Czeiter E, Szellár D, Dóczi T, Komoly S, Büki A. Biomarkerek szerepe koponyasérülésben/Biomarkers in traumatic brain injury. Clinical Neuroscience/ Ideggyógyászati Szemle. 2007 Jul 30;60(7-8):284-94.

IF: 0 Cit: 4 
2. Luckl J, Keating J, Greenberg JH. Alpha-chloralose is a suitable anesthetic for chronic focal cerebral ischemia studies in the rat: A comparative study. Brain Res. 2008 Jan 29;1191:157-67

IF: 2.494 Cit: 13

3. Czeiter E, Pal J, Kovesdi E, Bukovics P, Luckl J, Doczi T, Buki A. Traumatic axonal injury in the spinal cord evoked by traumatic brain injury. J Neurotrauma. 2008 Mar;25(3):205-13.

IF: 3.528 Cit: 9

4. Zhou C, Shimazu T, Durduran T, Luckl J, Kimberg DY, Yu G, Chen XH, Detre JA, Yodh AG, Greenberg JH. Acute functional recovery of cerebral blood flow following forebrain ischemia in the rat. J Cereb Blood Flow Metab. 2008 Jul;28(7):1275-84

IF: 5.741 Cit: 19

5. Kövesdi E, Lückl J, Bukovics P, Farkas O, Pál J, Czeiter E, Szellár D, Dóczi T, Komoly S, Büki A. Update on protein biomarkers in traumatic brain injury with emphasis on clinical use in adults and pediatrics. Acta Neurochir. 2010 Jan; 152 (1): 1-17

IF: 1.329 Cit: 59

6. Ferreira A, Milakara D, Alam M, Jorks D, Major S, Hartings J, Lückl J, Martus P, Graf, R, Dohmen Ch, Bohner, G, Woitzik J, Dreier J. Experimental and preliminary clinical evidence of an ischemic zone with prolonged negative dc shifts surrounded by a normally perfused tissue belt with persistent electrocorticographic depression. J Cereb Blood Flow Metab. 2010 Aug; 30 (8):1504-19.

IF: $\mathbf{4 , 5 2 2}$ Cit: 36

7. Kövesdi E, Bukovics P, Besson V, Nyirádi J, Lückl J, Pál J, Sümegi B, Dóczi T, Hernádi I, Büki A. A novel PARP- inhibitor L-2286 in a rat model of impact acceleration head injury: immuno-histochemical and behavioral study. Int. J Mol Sci. 2010 Mar 26; 11 (4):1253-68

IF: 2,279 Cit: 1 


\section{PRESENTATIONS RELATED TO THE SUBJECT OF THE THESIS}

1. Lückl J, Major S, Khojasteh U, Dreier JP. Quest for electrophysiological biomarkers in stroke translational research. Brain' 13, Shanghai 2013, China

2. Lückl J, Dreier JP, Sabados T, Wiesenthal D, Bari F, Greenberg JH. Peri-infarct flow transients predict outcome in rat focal brain ischemia. X. Conference of the Hungarian Stroke Society, Miskolc 2011, Hungary

3. Luckl J, Baker W, Sun Z-H, Durduran T, Yodh AG, Greenberg JH. Parameters of flow and oxyhemoglobin transients show spatial heterogeneity in rat focal brain ischemia. Brain'11, Barcelona 2011, Spain

4. Lückl J, Dreier JP, Szabados T, Wiesenthal D, Bari F, Greenberg JH. Flow transients predict outcome in rat focal brain ischemia. Brain'11, Barcelona 2011, Spain

5. Luckl J, Baker W, Sun Z-H, Durduran T, Yodh AG, Greenberg JH. Contralateral forepaw stimulation increases the incidence of hyperemic flow transients in focal ischemia in rat. Brain'09, Chicago 2009, USA

6. Luckl J, Zhou C, Durduran T, Yodh AG, Greenberg JH. Simultaneous monitoring of peri-infarct flow transients with laser speckle and laser Doppler during middle cerebral artery occlusion in rat. International Stroke Conference, New Orleans 2008, USA 